\title{
Groundwater seepage landscapes from distant and local sources in experiments and on Mars
}

\author{
W. A. Marra ${ }^{1}$, S. J. McLelland ${ }^{2}$, D. R. Parsons ${ }^{2}$, B. J. Murphy ${ }^{2}$, E. Hauber ${ }^{3}$, and M. G. Kleinhans ${ }^{1}$ \\ ${ }^{1}$ Faculty of Geosciences, Universiteit Utrecht, Heidelberglaan 2, 3584 CS, Utrecht, the Netherlands \\ ${ }^{2}$ Department of Geography, Environment and Earth Sciences, University of Hull, \\ Cottingham Road, Hull, HU6 7RX, UK \\ ${ }^{3}$ Deutsches Zentrum für Luft- und Raumfahrt (DLR), Institut für Planetenforschung, Rutherfordstraße 2, \\ 12489 Berlin, Germany
}

Correspondence to: W. A. Marra (w.a.marra@uu.nl)

Received: 4 February 2015 - Published in Earth Surf. Dynam. Discuss.: 19 February 2015

Revised: 18 June 2015 - Accepted: 3 July 2015 - Published: 4 August 2015

\begin{abstract}
Valleys with theater-shaped heads can form due to the seepage of groundwater and as a result of knickpoint (waterfall) erosion generated by overland flow. This ambiguity in the mechanism of formation hampers the interpretation of such valleys on Mars, particularly since there is limited knowledge of material properties. Moreover, the hydrological implications of a groundwater or surface water origin are important for our understanding of the evolution of surface features on Mars, and a quantification of valley morphologies at the landscape scale may provide diagnostic insights on the formative hydrological conditions. However, flow patterns and the resulting landscapes produced by different sources of groundwater are poorly understood. We aim to improve the understanding of the formation of entire valley landscapes through seepage processes from different groundwater sources that will provide a framework of landscape metrics for the interpretation of such systems. We study groundwater seepage from a distant source of groundwater and from infiltration of local precipitation in a series of sandbox experiments and combine our results with previous experiments and observations of the Martian surface. Key results are that groundwater flow piracy acts on valleys fed by a distant groundwater source and results in a sparsely dissected landscape of many small and a few large valleys. In contrast, valleys fed by a local groundwater source, i.e., nearby infiltration, result in a densely dissected landscape. In addition, valleys fed by a distant groundwater source grow towards that source, while valleys with a local source grow in a broad range of directions and have a strong tendency to bifurcate, particularly on flatter surfaces. We consider these results with respect to two Martian cases: Louros Valles shows properties of seepage by a local source of groundwater and Nirgal Vallis shows evidence of a distant source, which we interpret as groundwater flow from Tharsis.
\end{abstract}

\section{Introduction}

Valleys with theater-shaped heads exist in the landscapes of Earth and Mars. On Mars, examples of such valleys are Louros Valles (Fig. 1a) and Nirgal Vallis (Harrison and Grimm, 2005). Terrestrial examples can be found in the Atacama Desert in Chile (Irwin et al., 2014; Fig. 1b), on the Canterbury Plains in New Zealand, on the Colorado Plateau and on Hawaii (Schumm and Phillips, 1986; Howard and Kochel, 1988; Kochel and Piper, 1986; Craddock et al., 2012). Fur- thermore, much smaller examples that are similar in shape are valleys that emerge in eroding riverbanks (Fig. 1c) or those on the beach that develop during a receding tide (Higgins, 1982; Otvos, 1999; Fox and Wilson, 2010; Hagerty, 1991).

Such theater-headed valleys can form by the seepage of groundwater in erodible sediment (e.g., Howard and McLane, 1988). These valleys form due to headward erosion that is produced by mass-wasting processes where groundwater seeps to the surface (Fig. 2a). In this paper we define 


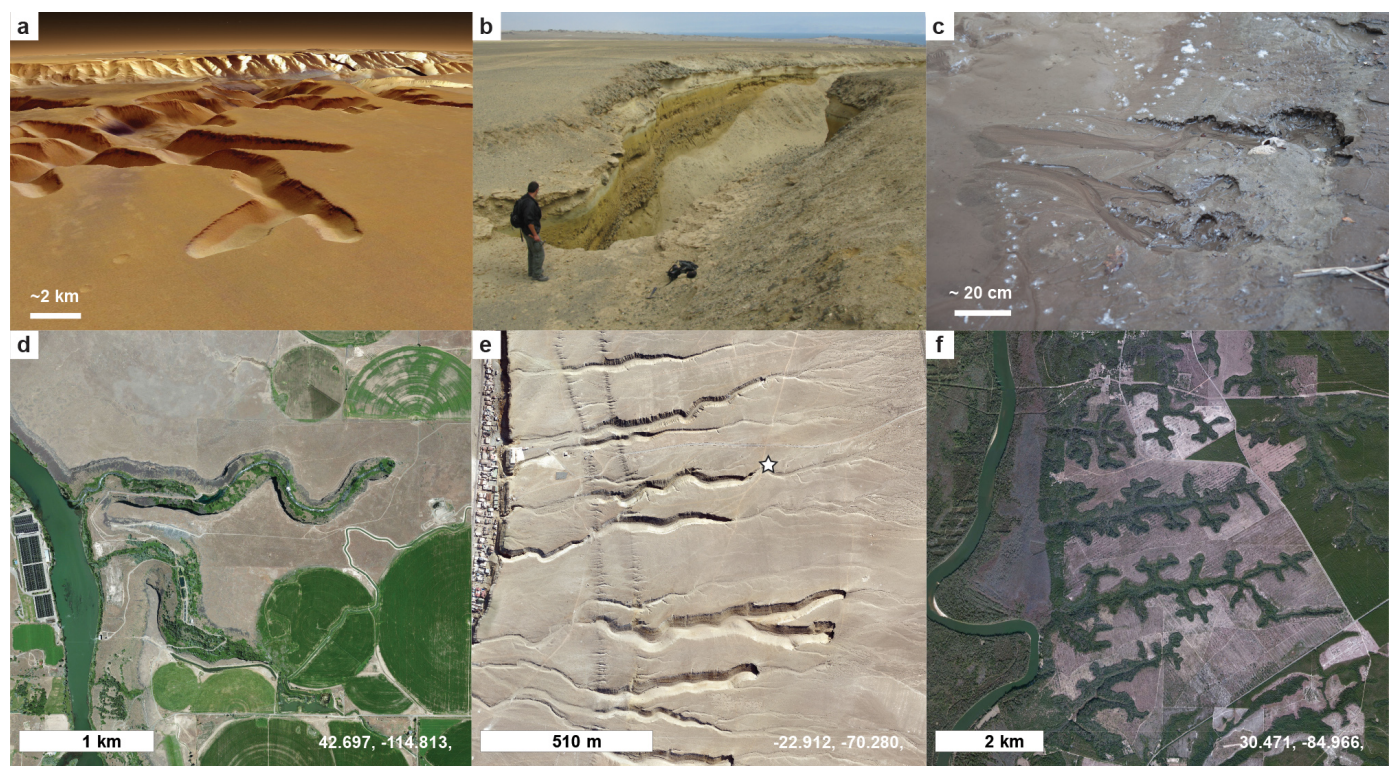

Figure 1. Examples of theater-headed valleys. (a) Louros Valles on Mars (perspective view); (b) valleys on the coast of the Atacama Desert, Chile (oblique photo, human for scale); (c) a riverbank (oblique photo); (d) side valleys of Snake River, Idaho, USA (orthorectified image); (e) valleys on the coast of the Atacama Desert, where the star indicates position of viewpoint of (b) (orthorectified image); (f) Apalachicola Bluffs near Bristol, Florida, USA (orthorectified image). Image credits: (a) Google Earth (NASA/USGS, ESA/DLR/FU Berlin), (b) Tjalling de Haas, (c) Wouter Marra, (d, f) Bing Maps Imagery, (e) courtesy of GFZ Potsdam.

seepage as the hydrological process of groundwater emerging at the surface and groundwater sapping as the geomorphological process of erosion by undercutting which is triggered by seepage, although not all erosion by seepage of groundwater results in undercutting. A channel is a body of flowing water, i.e., an active fluvial feature. A valley is an eroding (active) or eroded (inactive) depression in the landscape, usually linear, elongated or sinuous. Persistent fluvial erosion by a channel results in the formation of a valley larger than the channel, but other processes (glacial, mass wasting) can result in the formation of valleys as well. The morphology of former channel that did not result in the formation of a larger valley are referred to as channel remnants. Confusingly, in Martian geomorphology, large valleys formed by catastrophic floods are referred to as outflow channels; we conform to this definition for the outflow channels.

Valley formation by seepage (Fig. 2a) is different from valley formation by overland flow. In the former, headward progression is the result of knickpoint retreat and fluvial incision (Fig. 2b). However, overland flow can also produce similar theater-headed valleys when incising into a substrate with an erosion resistant top layer (Lamb et al., 2006). This process is a likely candidate for the formation of the theaterheaded valleys next to the Snake River in Idaho (Fig. 1d). The ambiguity in the mechanism of formation of the valleys hampers the interpretation of their origin based on their theater-shaped morphology alone. This ambiguity is particularly problematic for the explanation of theater-shaped valley heads on Mars, where direct field observations and material properties are lacking and a long period of weathering obscures morphological details.

The morphological properties of entire landscapes with multiple valleys may help in the interpretation of these Martian valleys when single entities have an ambiguous origin. An important mechanism for the landscape formation by groundwater seepage is groundwater flow piracy: since valleys are topographic depressions, they attract more groundwater from their surroundings, resulting in a decrease in discharge to nearby valleys (Howard and McLane, 1988). As a result, smaller valleys cease to develop in favor of larger valleys. Landscape metrics may show the presence of this feedback mechanism. Furthermore, splitting of valleys during their headward development (headward bifurcation) produces typical angles between valley segments (Devauchelle et al., 2012; Glines and Fassett, 2013). In the case of valley formation by seepage from uniform precipitation, the theoretical angle between valley segments becomes $72^{\circ}$ (Devauchelle et al., 2012). Such properties as well as the orientation of valleys (Jaumann and Reiss, 2002) can be extracted from the landscape and indicate the responsible hydrological system.

Our knowledge of groundwater seepage processes and their relation to landscape evolution is limited, particularly as systems with only groundwater processes are absent on Earth and previous studies have mostly been limited to the same boundary conditions of groundwater from an upstream constant-head tank (e.g., Howard and McLane, 1988; Lobkovsky et al., 2004; Schorghofer et al., 2004; Pornprom- 


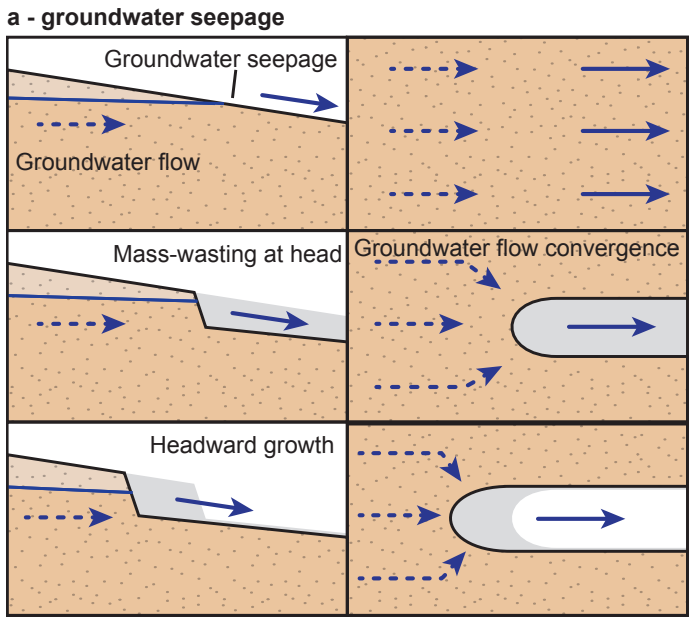

b - overland flow

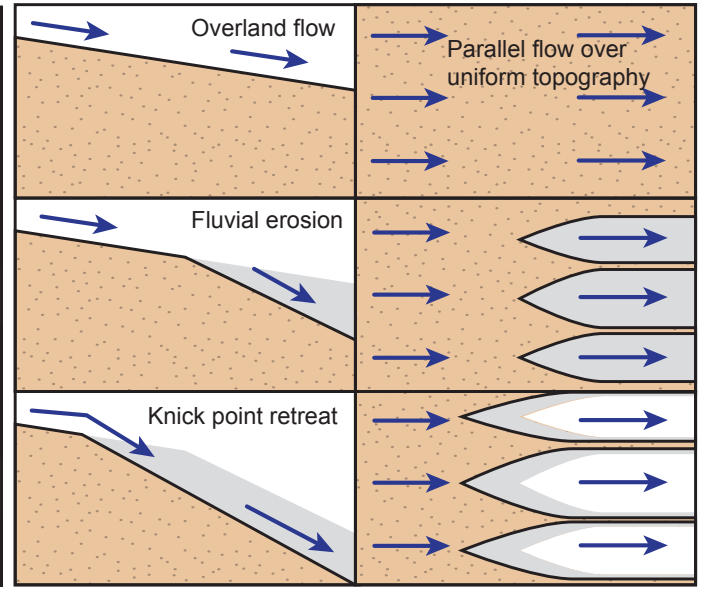

Figure 2. Fundamental processes at valley heads for overland flow and groundwater seepage. (a) Valleys formed by groundwater seepage extend in a headward direction by mass-wasting processes. (b) Valleys by overland flow deepen by fluvial incision and extend in a headward direction by knickpoint retreat.

min et al., 2010; Marra et al., 2014a). These experiments simulated a distant groundwater source and showed the basic morphology of valleys formed by groundwater seepage and also revealed the importance of groundwater flow piracy as a key process for valley evolution. However, alternate hydrological systems exist where other processes are significant and result in a different landscape evolution. In contrast to a distant groundwater source, groundwater seepage could come from nearby infiltration of precipitation. Such systems exist on Earth (Abrams et al., 2009; Fig. 1f) and have been studied in experiments to some extent (Berhanu et al., 2012), but require more attention in terms of their morphological impact on landscape dynamics. We hypothesize that a local groundwater source, e.g., as result of locally infiltrated precipitation, results in less groundwater flow piracy compared to groundwater that first travels some distance before seepage to the surface, because seepage from a nearby source is less influenced by the topographic gradient responsible for flow piracy. Since flow piracy is an important mechanism in the formation of valleys by groundwater seepage, we expect different and distinct morphological development for valleys formed by seepage from a local source compared to those produced by distally fed systems. Specifically, distant sources of groundwater produces landscapes with many small valleys that ceased developing early, whereas in landscapes produced by local sources of groundwater, valleys have similar lengths as most valleys developed continuously.

In this paper, we aim to improve our understanding of groundwater seepage processes, specifically on the resulting valley formation at a landscape scale using morphological experiments. We specifically study the difference in morphological development of valleys that result from a distant groundwater source (simulated with an upstream constanthead tank) and a local groundwater source (simulated by infiltrating precipitation). Furthermore, we combine our experimental insight with previous studies in order to show a complete range of landscapes formed by groundwater seepage under different conditions. The objective is to provide a framework that shows the arrangement of multiple valleys, i.e., the orientation and length distribution that results from different hydrological boundary conditions. These properties will aid in the identification of the formative processes when the single-valley morphology is ambiguous, and will constrain the underlying hydrological conditions. To demonstrate the application of this framework for landscape interpretation, we use two frequently cited cases of groundwater seepage on Mars, Nirgal Vallis and Louros Valles, and relate their landscape metrics to the possible sources of groundwater.

\section{Methods}

\subsection{Experimental design}

We conducted a series of flume experiments in the Total Environmental Simulator (TES) facility at the University of Hull to investigate the morphological development of theater-headed valleys by groundwater seepage. Moreover, with these experiments we simulated the difference between groundwater seepage generated by a distant source of groundwater, using a constant groundwater level at the upstream end of the experimental setup, and groundwater seepage produced by infiltration of precipitation applied over the entire experimental domain. We repeated both experiments with an idealized initial morphology and with a heterogeneous initial morphology that was the result of a previous experiment. In this section, we present the setup, the initial 
topography and applied boundary conditions across the experimental set.

The initial idealized morphology consisted of a volume of sand with a median grain size of $0.7 \mathrm{~mm}$, which comprised (1) a flat area of $1.7 \mathrm{~m}$ upstream and (2) a slope of $0.22 \mathrm{~m} \mathrm{~m}^{-1}$ for $3.5 \mathrm{~m}$ (Fig. 3), which was uniform over a width of $4 \mathrm{~m}$. We used natural, moderately angular sand to mimic natural groundwater and surface flow processes. The grain size was such that groundwater flow was neither too rapid nor too slow for the formation of valleys within a reasonable period of time. The sloping section ensured seepage of groundwater from a hydrostatic groundwater level, that is, without applying extra pressure to the groundwater.

The sediment was placed on top of a partially sloping impermeable floor to increase groundwater flow in the downstream half of the setup and to reduce the amount of sediment required. This floor was flat for $2.6 \mathrm{~m}$ and the slope was $0.11 \mathrm{~m} \mathrm{~m}^{-1}$ for $2.6 \mathrm{~m}$. Pond liner ensured the impermeability of the floor and walls. A rough cloth on top of the pond liner prevented the entire block of sediment from sliding down the smooth pond liner surface. The total sediment depth was $0.5 \mathrm{~m}$ in the upstream flat part, sloping towards the downstream end. At the downstream end, a row of $6 \mathrm{~cm}$ high bricks truncated the wedging slope to prevent the sediment from sliding down. In addition, the small spaces between these $10 \mathrm{~cm}$ wide bricks acted as initial surface perturbations. This ensured the initiation of channels was evenly distributed over the entire width of the sediment surface.

The constant-head tank was designed to simulate a distant groundwater source and was constructed opposite of the sloping wedge of sediment. It spanned the entire width and depth of the sediment fill with a $0.6 \mathrm{~mm}$ mesh fabric, braced with chicken wire and steel gratings at the water side to retain the sediment and avoid collapse into the reservoir under the weight of the sand. This setup enabled water from the constant-head tank to enter the body of sediment over the entire width and depth at the upstream side of the flat section of the sediment fill.

For the experiment with precipitation as the water source, we used an array of spray nozzles above the setup to supply water over the sediment surface. These nozzles were fed with a discharge such that the water spray infiltrated in the flat area and seeped out on the sloping wedge. The discharge feed was slightly lower than the infiltration capacity of the sediment. A rising groundwater table induced seepage, but, in contrast to the constant-head tank, the seepage areas were fed by nearby infiltrated groundwater. Twelve spray nozzles with square spray patterns were used to ensure uniform spray distribution and pressurized water was fed from a ring main to ensure equal spray rates for all nozzles.

We carried out five experiments with the above-described boundary condition combinations (Table 1) under terrestrial conditions. The experiment labeled distant source was carried out with the constant-head tank throughout as the boundary condition using the initial topography described above.
The final surface morphology from the distant source experiment was used as initial morphology of the experiment labeled local after distant, which was run with water input from the spray nozzles. The experiment labeled local precipitation was run with water input from the spray nozzles on the above-described initial topography. The experiment labeled local precipitation 2 was run to generate an initial morphology with the same conditions as local precipitation and this experiment was ceased early. The final morphology of local precipitation 2 was the initial morphology of distant after local, which was subject to groundwater flow generated by the constant-head tank.

\subsection{Experimental imagery and elevation models}

We captured the morphological development of the experiments using time-lapse photography. These images enabled us to study the experiments in detail from different angles. Moreover, we derived valley dimensions from orthorectified time-lapse images. The time-lapse setup consisted of six cameras (Canon PowerShot A640), mounted around the experimental setup (see C1-C6 in Fig. 3), which were triggered synchronously at set intervals. These intervals ranged from $30 \mathrm{~s}$ to $5 \mathrm{~min}$, based on the rate of morphological development during the ongoing experiment (values in Table 1).

For each experiment, time-lapse imagery from four cameras $(\mathrm{C} 1, \mathrm{C} 2, \mathrm{C} 4$ and $\mathrm{C} 5)$ was processed to construct a single orthorectified photograph (Fig. 3). Orthorectification was implemented using the "Image Processing" and the "Camera Calibration" toolboxes in the MATLAB software suite. Orthorectification was performed using the initial surface elevation model, due to absence of elevation data at each time step. This method resulted in warped imagery in areas with elevation change, i.e., within the valleys. However, these images were used to extract valley lengths and widths which are calculated from the distances between non-eroded valley walls. The outside edges of these walls form in the original surface and are therefore correctly represented in the orthorectified photograph using this method.

For detailed morphological analysis, we generated digital elevation models (DEMs) and orthorectified images at the end of each experiment using a large set of images and a structure-from-motion (SfM) algorithm (Forsyth and Ponce, 2011). In addition, we also acquired these data every day during the distant source and distant after local experiment at irregular intervals (Table 1). Each DEM and associated orthorectified image was derived from 70 to 100 digital images with about $80 \%$ overlap. We took these images by hand, allowing us to capture the area of interest. Twentyfour targets with known coordinates within the experimental setup enabled referencing of the images. Camera positions and orientations were solved using these known target coordinates and matched features between images. To improve the quality of the result, we removed features in wet areas to eliminate faulty matches in reflective areas due to differ- 

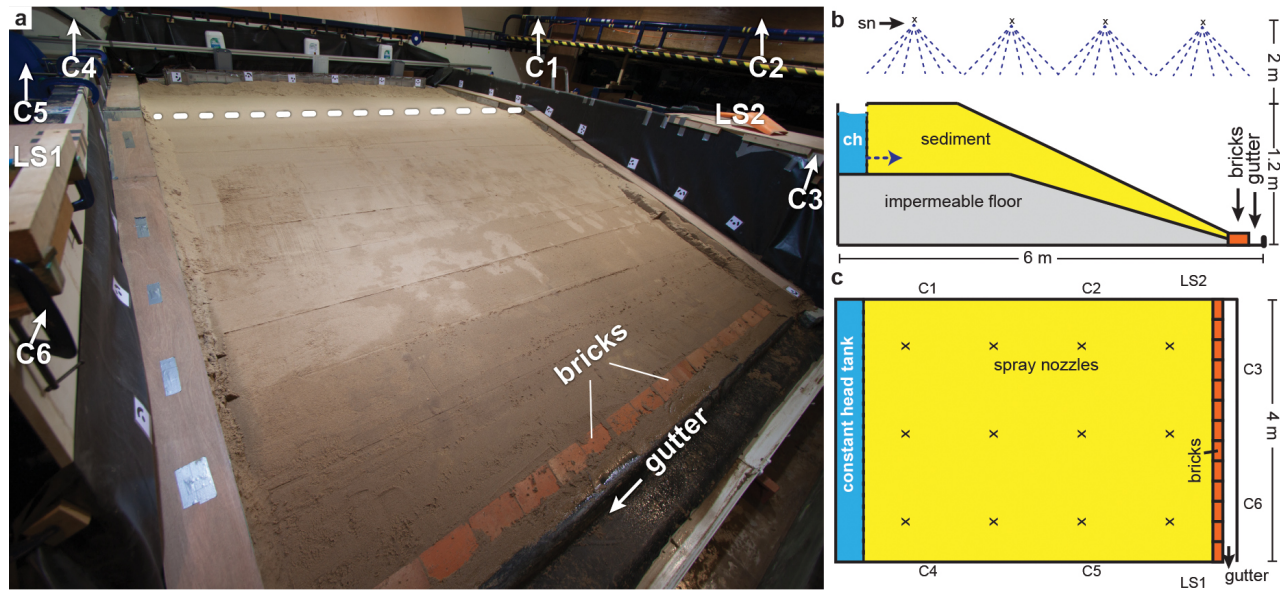

Figure 3. Setup of the experiments. (a) Oblique photo from downstream end of the flume, showing the initial sediment surface, gutter and constant-head tank in the back. The rain simulators and cameras are above the photographed area; their approximate locations (C1-C6) are shown. (b) Cross section showing setup with impermeable floor, constant-head tank (ch), gutter, approximate location of spray nozzles (sn) and brickwork. (c) Plan view showing the locations of the rain simulators (x), camera locations (C1-C6) and positions of the laser scanner (LS1, LS2).

Table 1. Experimental runs, their duration, discharge setting and data acquisition intervals; video number corresponds with videos in the Supplement. Abbreviation used: $\mathrm{d}$-days; $\mathrm{h}$ - hours; min - minutes.

\begin{tabular}{|c|c|c|c|c|c|c|}
\hline Experiment & Duration & $\begin{array}{l}\text { Mean } Q \\
\left(\operatorname{Lmin}^{-1}\right)\end{array}$ & $\begin{array}{l}\text { Cumulative } Q \\
\left(\mathrm{~m}^{3}\right)\end{array}$ & $\begin{array}{l}\text { Time-lapse } \\
\text { interval }\end{array}$ & SfM interval & Video \\
\hline Distant source & $3 \mathrm{~d} 3 \mathrm{~h}$ & 2.4 & 10 & $5 \mathrm{~min}$ & $\begin{array}{l}1 \mathrm{~d} 3 \mathrm{~h} \\
2 \mathrm{~d} 2 \mathrm{~h} \\
2 \mathrm{~d} 22 \mathrm{~h} \\
3 \mathrm{~d} 3 \mathrm{~h}\end{array}$ & video 1 \\
\hline $\begin{array}{l}\text { Local precipitation } \\
\text { Local precipitation } 2\end{array}$ & $\begin{array}{l}1 \mathrm{~h} 50 \mathrm{~min} \\
40 \mathrm{~min}\end{array}$ & 11.9 & 0.95 & $30 s$ & end of exp. & video 2 \\
\hline Local after distant & $3 \mathrm{~h} 10 \mathrm{~min}$ & 10.5 & 1.9 & $30 \mathrm{~s}$ & end of exp. & video 3 \\
\hline Distant after local & $3 \mathrm{~d} 16 \mathrm{~h}$ & 2 & 10 & $5 \mathrm{~min}$ & $\begin{array}{l}0 \mathrm{~d} 2 \mathrm{~h} \\
0 \mathrm{~d} 21 \mathrm{~h} \\
2 \mathrm{~d} 0 \mathrm{~h} \\
2 \mathrm{~d} 20 \mathrm{~h} \\
3 \mathrm{~d} 16 \mathrm{~h}\end{array}$ & video 4 \\
\hline
\end{tabular}

ent lightning angles between images. Elevation models were generated for each set of images, which were processed to a gridded elevation model with $1 \mathrm{~mm}$ cell size and a $0.5 \mathrm{~mm}$ orthorectified images. We used a Canon 550D DSLR camera with an $18-55 \mathrm{~mm} \mathrm{f} / 2.8$ lens to take the photos, which we processed in RAW format to 16 bit TIF images to eliminate compression artifacts. We used Agisoft PhotoScan for SfM processing (Agisoft, 2014).

A laser scanner was also used to obtain DEMs at the end of each experiment. Point-cloud elevation data of the final morphology were scanned from two different angles in order to eliminate data shadows outside the line of sight of the laser scanner (see Fig. 3). These point clouds were oriented and merged using fixed targets in the experimental setup to produce a combined scan gridded onto a DEM with a $2 \mathrm{~mm}$ cell size. We used a Leica ScanStation 2 laser scanner for data acquisition, CloudCompare for point-cloud orientation and ArcGIS for gridding of the point-cloud data.

\subsection{Valley development and erosion rates}

To quantify the morphological development, we measured valley widths, lengths and depths during the experiments. Based on these data, we calculated valley shapes, and erosion rates and compared the latter to measured sediment output.

The length $L(\mathrm{~m})$ and width $W(\mathrm{~m})$ of each valley that formed during the experiments were determined for each time-lapse interval from the orthorectified time-lapse images. The valley width was taken just downstream of the valley head where the valley walls were parallel. Valley depth 
$D$ (m) was defined as the deepest point of each valley, i.e., the largest elevation difference between the original surface and the eroded surface. Valley depth was measured at each $\mathrm{SfM}$ interval. The final valley floor slope $S_{\mathrm{f}}\left(\mathrm{m} \mathrm{m}^{-1}\right)$ was extracted from the final DEM. We defined the valley floor as the lowest point in each valley cross section. We estimated the erosion rates of each valley during the experiments by combining the valley dimensions and valley shapes.

First, the eroded volume $V\left(\mathrm{~m}^{3}\right)$ was estimated as

$V=W \times L \times D \times \mathrm{SI}_{\mathrm{c}} \times 0.5$,

for which $W$ and $L$ were taken at each time-lapse interval, $D(\mathrm{~m})$ is the valley depth that was interpolated between SfM measurements for each time-lapse interval. $\mathrm{SI}_{\mathrm{c}}$ is the shape index of the valley cross section, which is the average ratio of the actual valley cross section to the square cross section of $W \times D$. The factor 0.5 corrects for the longitudinal profile of the valley, which is in all cases approximately triangular. Valley volume was transformed into an erosion rate $E\left(\mathrm{~g} \mathrm{~s}^{-1}\right)$ :

$E=\frac{\Delta V \rho_{\mathrm{s}}(1-n) \times 10^{-3}}{\Delta T}$,

where $\Delta V$ is the change in volume, $\rho_{\mathrm{s}}$ is the density of sand $\left(2300 \mathrm{~kg} \mathrm{~m}^{-3}\right), n$ the porosity of the sediment $(0.3)$ and $\Delta T$ (s) is the time over which the change in volume occurred. Cumulative erosion was compared to sediment output measurements collected from bucket traps.

\subsection{Martian landscape metrics}

We constructed elevation profiles and extracted the orientation in degrees from north (i.e., azimuth) of valley segments, the angles between converging valleys and valley lengths of Louros Valles and Nirgal Vallis. Elevation profiles were extracted from HRSC image H0380_0001 (125 m resolution DEM) for Louros Valles; valleys of Nirgal Vallis were too small to produce elevation profiles. Valley segments for both systems were digitized from THEMIS daytime infrared mosaic (Fergason et al., 2013) and HRSC (Jaumann et al., 2007) imagery. We distinguished different stream orders, based on the Hack stream-ordering number (Hack, 1957). In this system, the first order is the main, downstream, valley; the first tributary is the second order and so on. We choose this system since it represents the chronology of valley formation by headward erosion.

The data set of valley segments was transformed to a network topology to distinguish between upstream and downstream directions, using logical operators based on the methods described in Marra et al. (2014b) using ArcGIS and MATLAB. In this data set, we identified converging valley segments, valley heads and outlets based on the network topology. Building upon the work of Jaumann and Reiss (2002), the orientation relative to north of each valley segment was extracted for each stream order identified in the data set. Orientation distributions were normalized per stream order to clearly show the differences between valley orientations of different stream orders. At each node of converging valleys, we calculated the angle between the upstream valley segments (following Glines and Fassett, 2013). Such a converging valley is referred to as headward bifurcation; this definition relates to the chronological order of events in valley formation. In active rivers, the term bifurcation is used for a fluvial channel that splits into two in the downstream direction, which relates to the direction of water movement. Furthermore, for each valley head in the network, we calculated the distance to the first lower-order valley segment.

\section{Experimental results}

In the following section, we first describe the observed morphological development during the experiments, and then we link this morphological development to the acting processes. Time-lapse imagery and elevation models support these observations (time-lapse movies are available in the Supplement).

\subsection{Distant source}

The experiment with seepage from a distant constant-head tank was characterized by slowly developing valleys. This experiment took over 3 days to complete and was carried out with a constant discharge of $2.4 \mathrm{~L} \mathrm{~min}^{-1}$ (Table 1).

The sediment saturated in the first hours of the experiment. During this stage, a visible wetting front at the surface progressed from the upstream constant-head tank in the downstream direction. The sediment became fully saturated at the foot of the slope where seepage occurred after $2.5 \mathrm{~h}$ over the full width of the sediment surface (Fig. 4a-i). The initial seepage pattern remained roughly the same, though the seepage area extended upslope to about $1 \mathrm{~m}$ from the foot of the slope. Initially, the seepage was too low for fluvial transport to occur. As the seepage rate increased, fluvial transport started after $4 \mathrm{~h}$ and the first channels started to form at the foot of the slope within the seepage area.

The initial channels at the foot of the slope featured a combination of mass-wasting and fluvial processes. Mass wasting of saturated sediment at the head caused headward erosion, and fluvial processes in the channel resulted in incision and the formation of valleys (Fig. 4a-iii). As the valleys developed in the upstream direction, the seepage area retreated and seepage focused within the valleys as shown by drying of the sediment between the valleys and a concurrent increase in discharge within the valleys (Fig. 4a-iii). Seepage was limited to a declining number of valleys, as the valleys that reached most upstream progressively attracted more groundwater. From the 10 valleys that started to form in the initial stage of the experiment, only 6 remained active after a few 


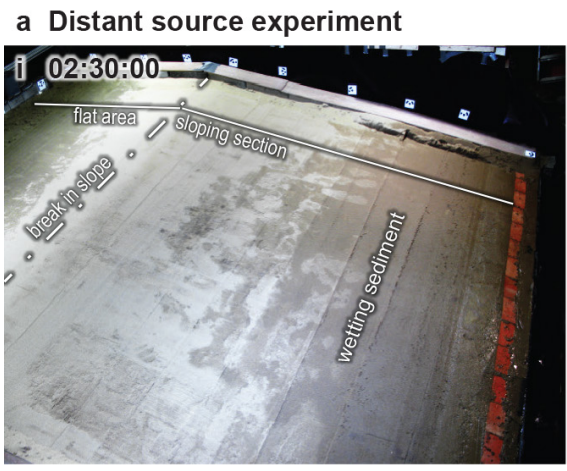

b Local precipitation experiment
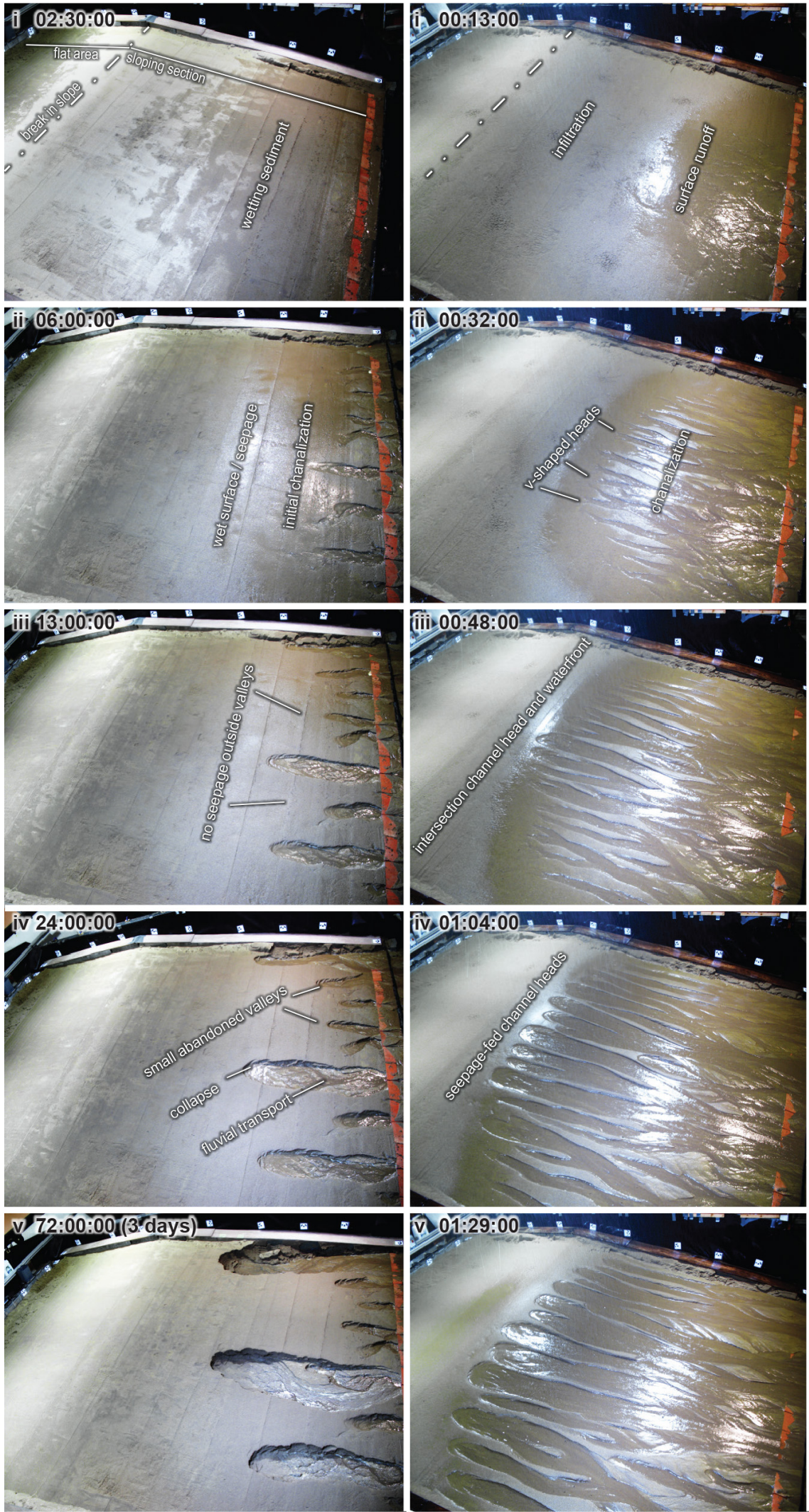

Figure 4. Stills from time lapses of the experiments showing the main morphological development. Full time-lapse movies are available in the Supplement. 
hours (Fig. 4a-iv), and only 3 remained active for several days (Fig. 4a-v).

The decreasing number of actively developing valleys illustrates the process of groundwater flow piracy as the largest valleys attract most of the groundwater flow since these are the deepest point in the landscape. As a result, more groundwater is directed to those largest valleys, which are therefore more active and smaller valleys cease developing. This feedback resulted in a final morphology with a few large and several small valleys (Fig. 5).

The remaining valleys grew and as they became deeper, the head- and side walls gained strength by cohesion as the sediment was moist. As a result, the headwall retreat was governed by collapse due to undercutting at the toe, in contrast to the slumping of the entire valley head before the development of this cohesive top layer. In this process, the toe of the head wall was destabilized by fluvial erosion, resulting in collapse of the headwall. The collapsed material spread over a distance of 0.1 to $0.2 \mathrm{~m}$ into the valleys. Fluvial transport removed this material from the upstream end to the downstream end of the experimental setup. These processes showed a cyclic behavior: head collapse only occurred after a destabilization of the head due to the removal of the sediment by fluvial transport. This cycle is essential for the continuation of the process as the valley head would stabilize without such erosion and sediment transport. The final morphology shows the former presence of these various processes. In the three most developed valleys, the upstream end had a steeper slope than the downstream sections with a break in slope separating the two (Fig. 6a). This change in slope is the result of the transition of mass-wasting processes upstream to fluvial processes downstream.

The collapse of unsaturated material at the valley heads resulted in steep head walls (Fig. 5). The step-wise increase in valley width and length shows distinct peaks of collapse (Fig. 7a and b) and erosion rates (Fig. 7d). Steps in width and depth of the valleys are not simultaneous, which shows that collapse of the head- and side walls occurs at different moments. Although erosion takes place in distinct peaks of activity, these valleys show a linear trend in valley length and width during the most part of their development. Interestingly, the width-to-length ratio of the three main valleys is the same during the entire experiment (Fig. 8a).

\subsection{Local precipitation}

The local precipitation experiment took $1 \mathrm{~h}$ and $50 \mathrm{~min}$ with an average discharge of $11.9 \mathrm{~L} \mathrm{~min}^{-1}$. This discharge is higher than in the distal source experiment. A part of the precipitation fell directly into the valleys since the precipitation was distributed evenly over the experimental domain. Furthermore, the groundwater table in the local precipitation experiment was close to the surface compared to a relative deep groundwater table in the distal source experiment. As a result this setup allowed for more seepage due to the higher seepage area, explaining the higher discharge and shorter run of this experiment. In this experiment we distinguished two stages in valley development. In roughly the first half of the experiment, overland flow was the main source of water feeding the channels. In the second half, groundwater fed the channels.

In the first stage of the experiment, the sediment in the downstream part of the slope saturated rapidly due to the limited sediment thickness (Fig. 4b-i). On this saturated sediment, precipitation transformed directly into runoff, resulting in channels that formed valleys by fluvial incision. These valleys formed over the entire width of the sediment and had valley heads with a V-shaped planform (Fig. 4b-ii). During this stage, valleys developed in a headward direction by fluvial erosion and valley heads were within the area of saturated sediment. Seepage inherently occurred in the valleys due to the setup of the experiment. However, the overland flow processes dominated the seepage processes.

As the groundwater table rose during the experiment, the boundary of saturated sediment moved upslope. This progression of the saturated area slowed down as it progressed. In the first stage, valley development did not keep up with this moving front. However, the valleys caught up and developed upstream of the saturated area as the experiment progressed (Fig. 4b-iii). This marks the second stage in valley development wherein groundwater seepage rather than surface runoff fed the valley heads. From the moment the valley heads were fed by groundwater, their planform changed from $\mathrm{V}$-shaped to theater-shaped (Fig. 4b-iv and b-v). This change indicates a change from fluvial flow to mass-wasting processes at the headwall. The headward growth showed similar characteristics to that in the experiment with seepage from a distant source: growth governed by failure of the headwall and fluvial transport that removed the failed material. Similar to the distant source experiments, there was also a distinguishable difference in slope in the upstream and downstream half of the valleys (Fig. 6), although this difference was less pronounced.

The valleys in the local precipitation experiment were shallow compared to the valleys in the distant source experiment. In both cases, the valleys developed around the groundwater table, which was close to the surface in the local precipitation experiments. The limited depth was presumably the result of the high groundwater table; there was no zone of unsaturated sediment resulting in valleys without steep walls (Figs. 5b and 6a).

The valleys in the local precipitation experiment became longer and slightly wider by lateral erosion during the experiment (Fig. $7 \mathrm{f}$ and g). An important difference with the distant source case was that all valleys continued to develop and had similar sizes during the experiment (Fig. 7i). This is due to the absence of groundwater flow piracy since each valley was fed by locally infiltrated groundwater (Fig. 5). In contrast to the valleys from a distant source, the relation between valley length and width in the locally fed valleys is not linear and different valleys do not have the same ratio (Fig. 8b). 


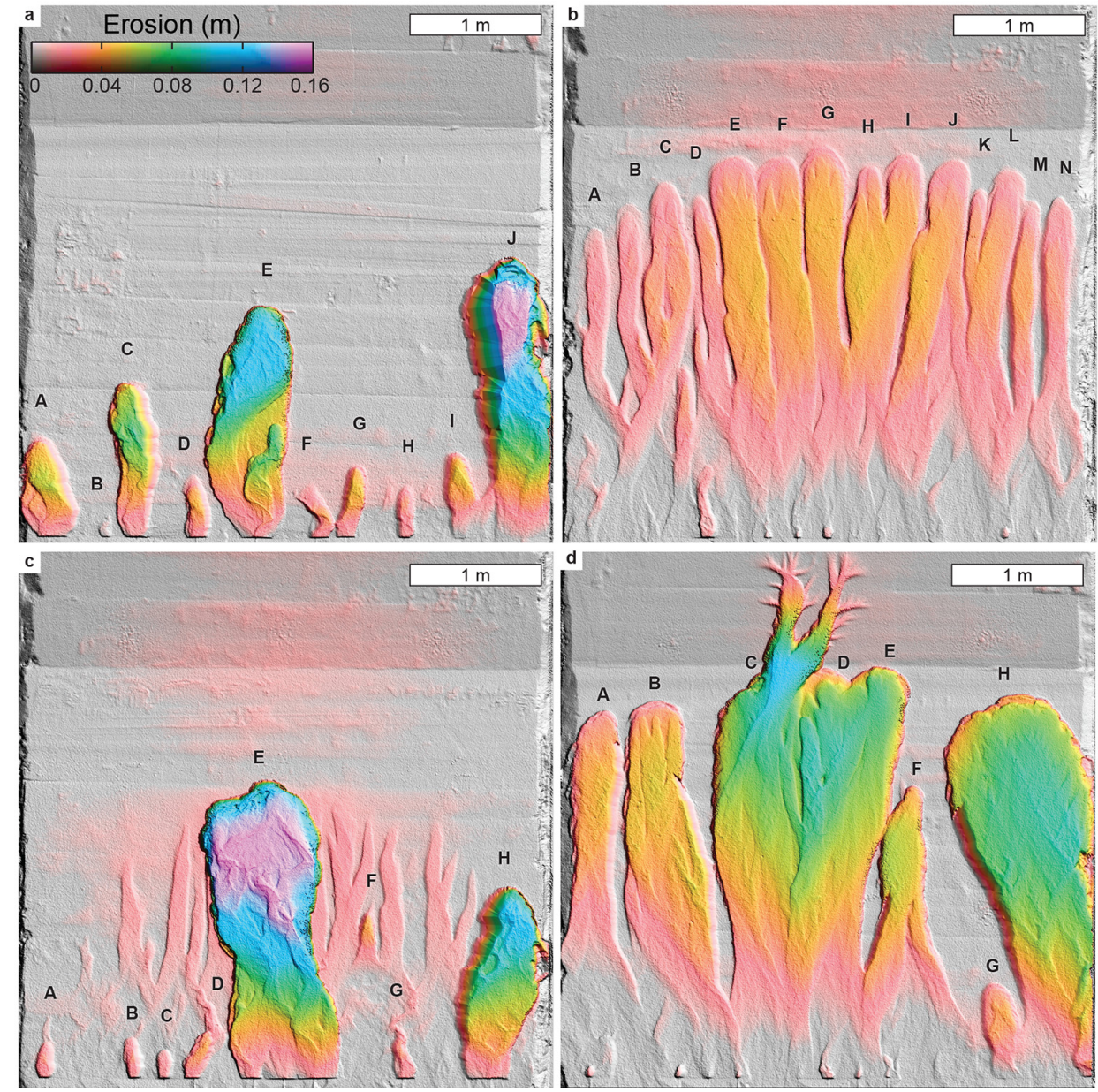

Figure 5. Erosion maps/final morphology of the experiments showing valley letters used in subsequent figures. (a) Distant source experiment, (b) local precipitation experiment (c) distant after local experiment and (d) local after distant experiment.

\subsection{Effect of initial morphology on seepage from a distant source}

We studied the effect of an initial morphology on the valley development in experiment distant after local by repeating the experiment on an initial morphology. This initial morphology was the result of experiment local precipitation 2, which consists of multiple parallel shallow valleys created by overland flow (Fig. 9).

Experiment distant after local showed the same general characteristics and development as the distant source experiment; the main difference is where valleys started to form. In the distant after local experiment, initial seepage at the downstream end focused within the valleys of the initial morphology. However, due to groundwater flow piracy, only a limited number of these valleys fully developed. Six valleys started to form, but only two valleys fully developed (Fig. 5c). Development in the two remaining valleys was the same as described for the distant experiment. In the early stages of valley development, the valleys followed the path of the existing valleys in the initial morphology. When they became larger, they still followed the path of the initial valleys, although these were straight and the new valleys were much wider than the initial valleys. In our view, these mature valleys seemed to develop independently from the initial morphology.

\subsection{Effect of initial morphology on local precipitation experiment}

In the local after distant experiment, the final morphology of the distant source experiment acted as the initial morphology of this run (Fig. 5a). The same processes acted in this experiment, though the initial morphology had a much larger effect on the final morphology in this case.

In the first stage of the local after distant experiment, the existing valleys reactivated as the sediment saturated. Due to the rising groundwater level, the steep side- and headwalls of the previous valleys became unstable and collapsed. This resulted in a decreasing valley depth and increasing width. The valleys that were abandoned in the distant source experiment 

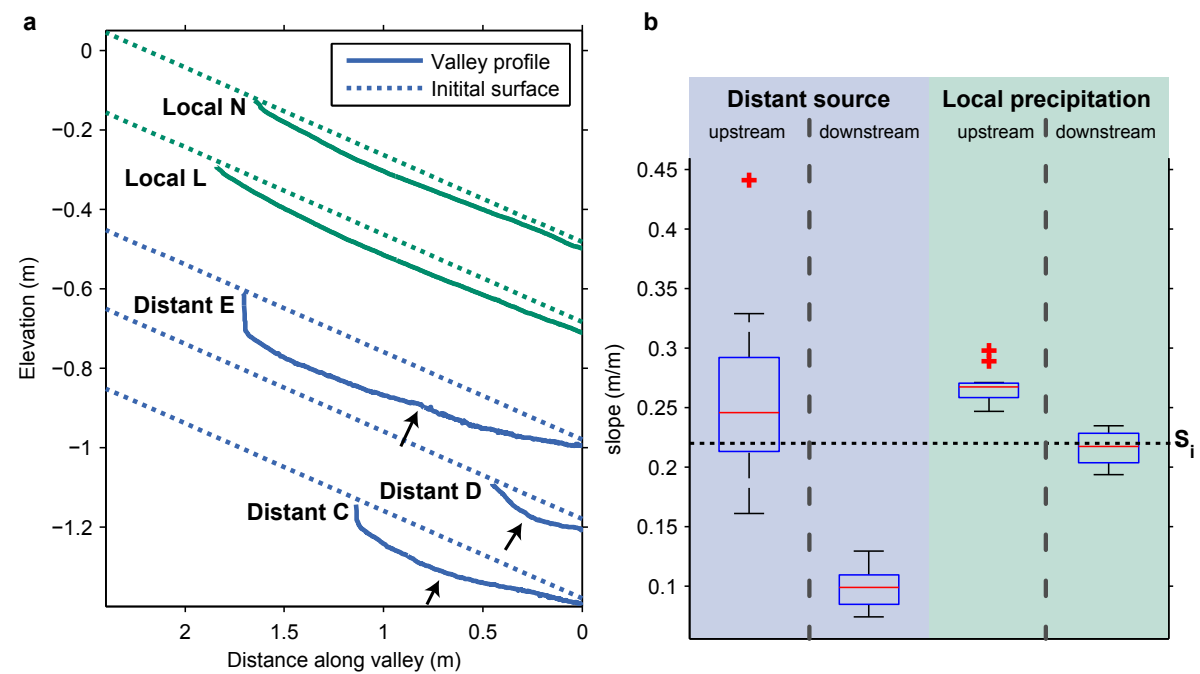

Figure 6. Valley profiles and slopes. (a) Profiles of valleys C, D and E of the distant source experiment and valleys $\mathrm{N}$ and L of local precipitation experiment, displayed with factor of 2 vertical exaggeration. Elevations are arbitrary and plotted with offset for clarity. The three distant source experiment profiles show three arrested stages of development also seen in larger valleys: incipient valley without a steep valley head (D), developing valley with moderate steep valley head (C) and developed valley with steep valley head and reduced valley floor gradient (E); arrows indicate break in slope at the valley floor. (b) Box plot of slope in upstream and downstream part of all valleys of the distant source $(n=9)$ and local precipitation $(n=14)$ experiments. The horizontal dotted line shows the initial surface slope $S_{\mathrm{i}}=0.22$.

due to groundwater flow piracy reactivated as they were fed by local precipitation and subsequently infiltrated groundwater, resulting in a smaller difference in valley size (Fig. 5d) compared to the initial situation (Fig. 5a). Collapse of the headwall caused headward erosion and lateral erosion caused widening of the valleys. These are the same processes as in the local precipitation experiment with no initial morphology, but the final morphology showed much wider valleys. The initially present valleys were relatively deep in comparison to the final valleys. The reduction in depth of these valleys corresponded with this widening.

At the end of the local after distant experiment, water ponded at the upstream flat section of the experimental setup. This ponding seemed to be the result of the sediment becoming fully saturated towards the end of the experiment. The headward developing valleys tapped into this shallow reservoir, resulting in a final slightly catastrophic stage of erosion due to the breach of this reservoir (Fig. 5d). This stage is not representative of the main objectives of this paper and therefore not further considered here.

\section{Examples of Martian valley systems}

In this section, we show the morphology of Louros Valles and Nirgal Vallis (Figs. 10 and 11), two Martian valley systems that were previously attributed to a groundwater seepage origin (e.g., Jaumann and Reiss, 2002; Harrison and Grimm, 2005; Glines and Fassett, 2013). These two system serve as an example of how to apply our experimental results and have received much attention in recent literature. Further- more, these systems show branching valleys, which also aids the interpretation of these systems. In this section, we describe Louros Valles and Nirgal Vallis; their interpretation is part of the discussion.

\subsection{Louros Valles}

Louros Valles is located at the north and south flanks of Valles Marineris. These valleys have circular valley heads cutting into flat plains. The valleys have a total relief of several kilometers and are between 10 and $100 \mathrm{~km}$ long (Fig. 10b and c). Upstream of the valley heads, there are no visible tributaries or depressions in the elevation data or imagery. Downstream of the valleys, in Valles Marineris, there are no clear deposits associated with these valleys. Sediment output in this case could be spread over a large area on the floor of Ius Chasma as a thin veneer and not recognizable as fluvial deposits. The valleys on the northern flank are shorter than the valleys at the south. Of the southern valleys, there are two larger valleys in the west; all other valleys are approximately equal in size. The valleys are closely spaced and several valleys touch or intersect, resulting in a relatively densely dissected plain (Fig. 10c and d).

As an example, we show an elevation profile of the largest valley of Louros Valles (Fig. 10e). These and other elevation data show a rough, irregular profile, likely related to postvalley formation wall collapse or tectonism. At the downstream end of the valley, the elevation quickly drops, which shows the onset of Valles Marineris. Based on a $10 \mathrm{~km}$ moving average, we show the valley has a change in slope about 

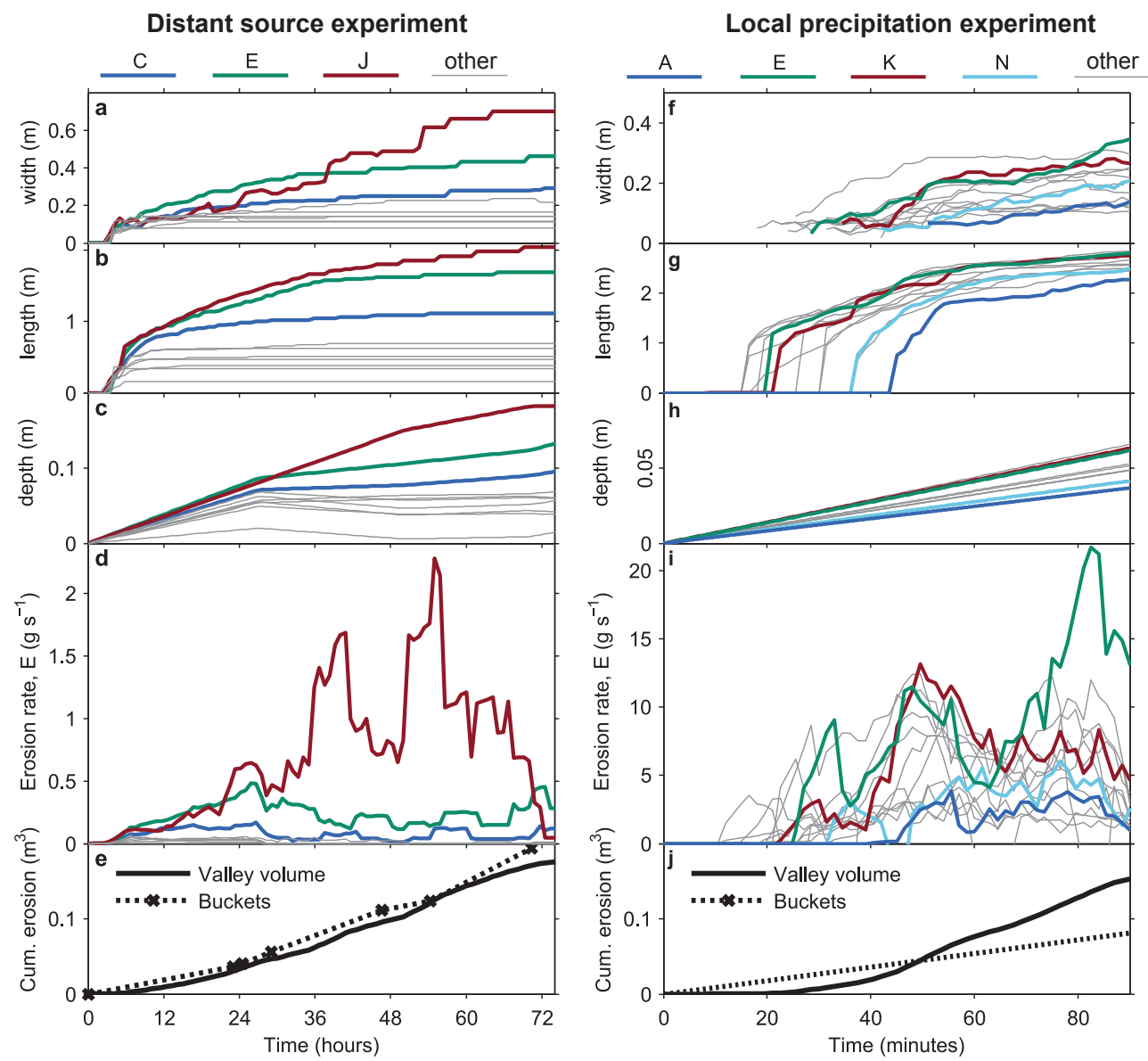

Figure 7. Valley development in the distant source (left panel) and local precipitation (right panel) experiments. Main valleys indicated with colors; letters in legend correspond with letters in Fig. 5. (a, f) Valley width and $(\mathbf{b}, \mathbf{g})$ length derived from orthorectified time-lapse imagery, $(\mathbf{c}, \mathbf{h})$ valley depth derived from SfM DEMs, $(\mathbf{d}, \mathbf{i})$ estimated erosion rated from these properties and (e, $\mathbf{j})$ total cumulative erosion estimate from valley volume compared to measured sediment output.
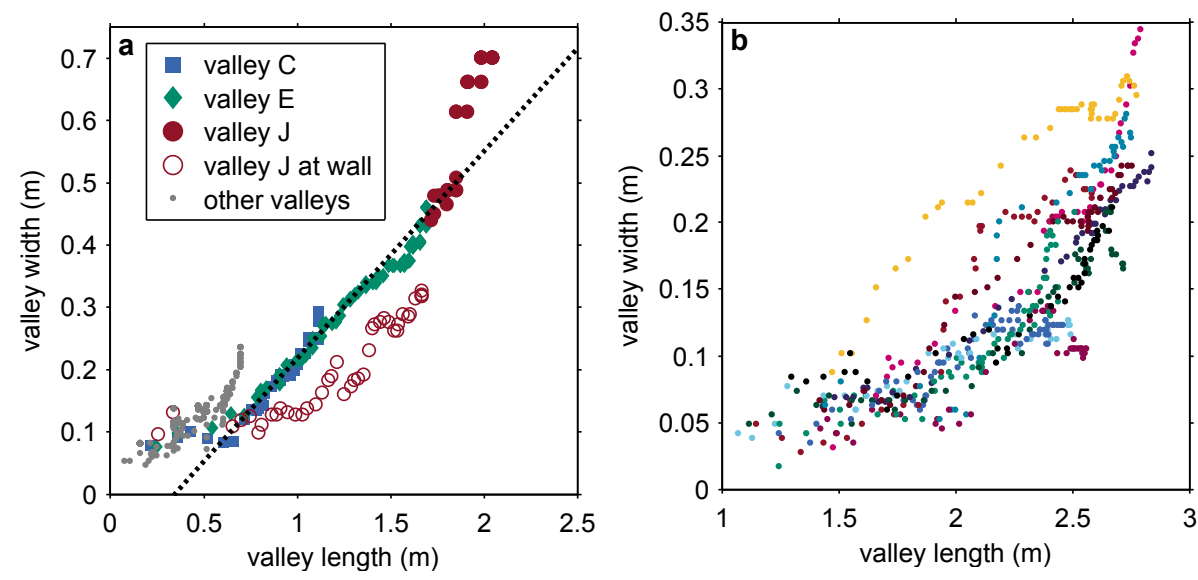

Figure 8. Development of valley width vs. length of the (a) distant source and (b) local precipitation experiment. Colored symbols in (a) represent the three main valleys. Values are plotted for all time-lapse intervals (valley dimensions increase with time). The open symbols in (a) represent valley dimensions when the measured valley section flowed at the side wall which influenced the valley width. Dotted line indicates trend of the three persisting valleys when the flume wall did not influence their width. 


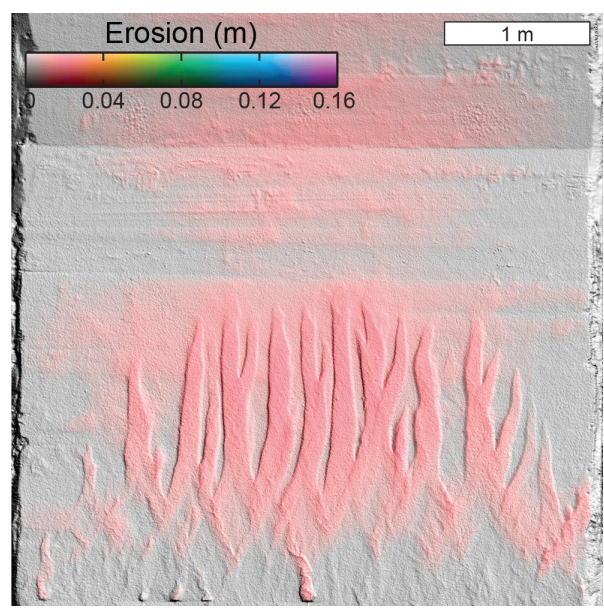

Figure 9. Final morphology of experiment local precipitation 2, which is the initial morphology of experiment distant after local.

halfway to a lower slope than the upstream part (Fig. 10e). However, the irregular elevation data limit the interpretation of these observations.

All valleys show headward bifurcations. For the northern valleys, the orientation of the first-order valleys varies from northwest to northeast, with most valleys oriented to the north-northeast (Fig. 12). The first tributaries, or second order (Hack, 1957) valleys, have a similar spread in orientation, but most are oriented to the west-northwest. For the southern valleys, most first-order valleys are oriented towards the southwest, while higher-order valleys are directed towards the south-southwest or towards the west-southwest (Fig. 12b). Interestingly, a few third- and fourth-order segments are oriented in the opposite direction $\left(180^{\circ}\right)$ to the first-order valleys (e.g., Fig. 10d).

The lengths of the tributaries range between 5 and $15 \mathrm{~km}$ (the main valleys are longer, but most are outside the graph), with no specific trend in the distribution of valley length (Fig. 12d). Mean headward bifurcation angles of the different stream orders are between 70 and $90^{\circ}$ (Fig. 12f).

\subsection{Nirgal Vallis}

Nirgal Vallis consists of a $>500 \mathrm{~km}$ long main valley and several sparsely distributed side valleys of various sizes (Fig. 11). Valley depths range from several tens to several hundreds of meters. The valley cuts into the plateau through several north-south-oriented wrinkle ridges, which are in places the highest points in the landscape. Several side valleys align with these wrinkle ridges (Glines and Fassett, 2013).

The orientation of the main valley is dominantly westnorthwest; the first-order tributaries have the same dominant orientation, but a large part is deflected north- and southward (Fig. 12c). This tendency of dominantly westward-oriented valleys is shown in the landscape (Figs. 11d and 12c). There are a few larger side valleys, but most side valleys are very short (Figs. 11d and 12e). This results in the sparsely dissected landscape. The mean headward bifurcation angle between valleys is $70.7^{\circ}$ with a standard deviation of 18.6 (Fig. 12g), similar but slightly less than the results of Glines and Fassett (2013) for the same valley network but with less measured junctions. Headward bifurcation angles are similar for different stream orders.

\section{Discussion}

\subsection{Valley morphology related to groundwater source}

The valleys in our experiments with a distant source of groundwater have semi-circular, theater-shaped valley heads with a sharp transition to the upstream, uneroded surface. These are similar to those found in previous studies on valleys formed by groundwater seepage (e.g., Howard and McLane, 1988; Hagerty, 1991; Dunne, 1980; Fox et al., 2006; Pornprommin et al., 2010). Valleys in our experiment fed from nearby infiltrated precipitation also featured semicircular valley heads but lacked the steep theater-shaped head wall. The valleys from both boundary conditions developed in a headward direction by destabilization of the valley head due to either undercutting or slumping. The eroded material is transported along the valley by fluvial processes. These two main processes showed a cyclic behavior as the fluvial erosion in the valley was the trigger for collapse at the valley head. Furthermore, in both experiments, the slope in the upstream section of the valley floor was steeper than in the downstream valley floor (Fig. 6), which relates to the transition from mass-wasted material released at the valley head to the fluvial transport of material downstream.

The morphological similarity between theater-headed valleys in groundwater sapping features (undercutting and failure by groundwater seepage erosion) at the beach (Higgins, 1982), in sandbox experiments (Howard and McLane, 1988), on the Colorado Plateau (Laity and Malin, 1985) and on Mars is often used as an argument for a groundwater origin of the Martian valleys (e.g., Schumm and Phillips, 1986; Mangold and Ansan, 2006; Harrison et al., 2013). A complication in the study of such morphology on Mars is that different processes yield a similar morphology. For example, waterfall erosion (Lamb et al., 2006) or groundwater weathering (Pelletier and Baker, 2011) can also produce theater-headed valleys. We do not solve this controversy in this paper since the experiments here do not explore the morphological differences between all these possible processes. Here, we focus on morphology related to groundwater flow processes and subsequent erosion in further detail and provide metrics of entire landscapes to aid the interpretation of Martian landscapes.

In the following discussion, we start by considering the applicability of our experiments. Then, we propose different end-member landscapes based on knowledge from our ex- 


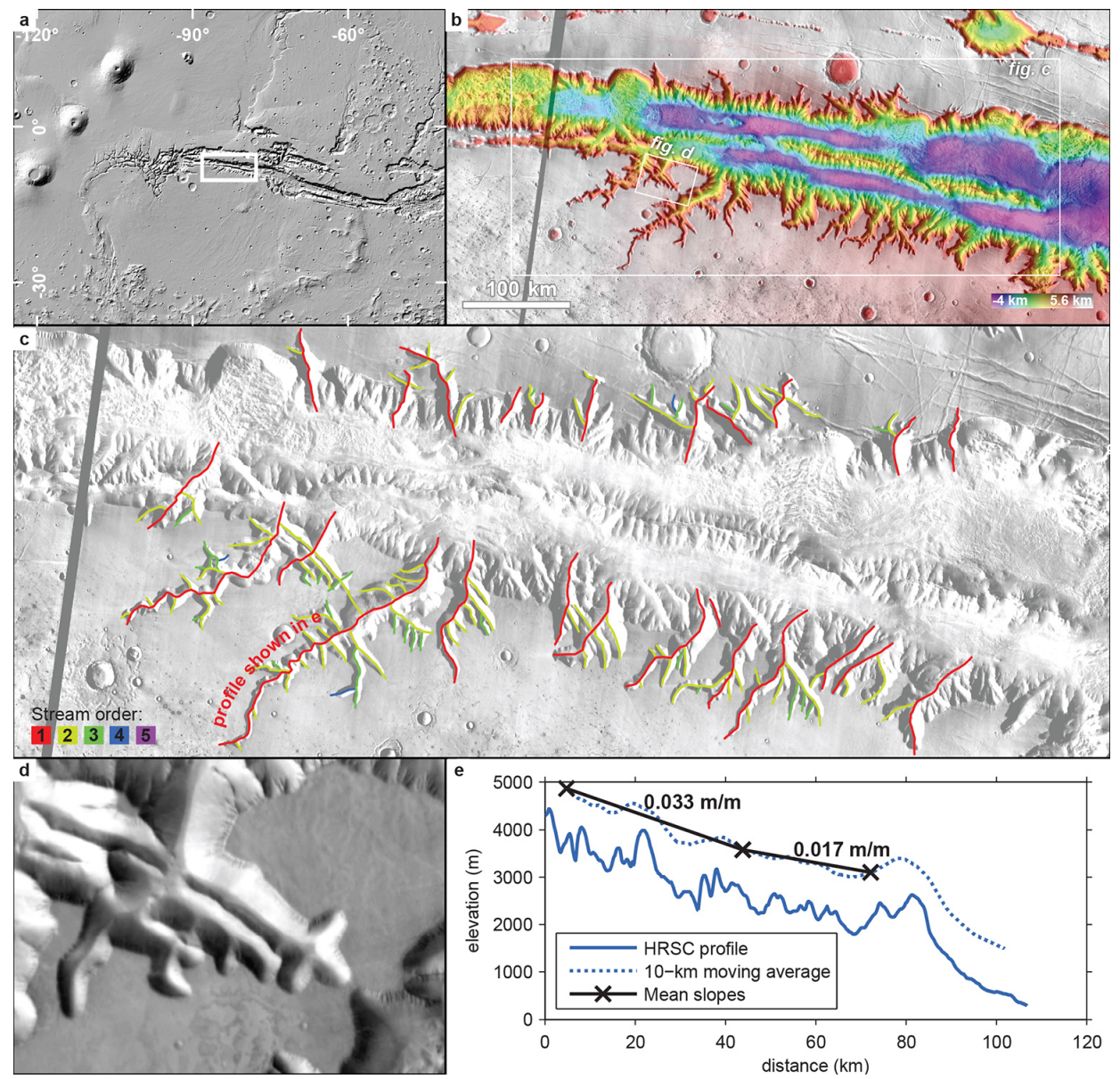

Figure 10. Maps and profile of Louros Valles. (a) Overview map showing location of (b) (MOLA shaded relief). (b) THEMIS daytime infrared mosaic with color-coded MOLA DEM, showing location of (c) and (d). (c) Valley centerlines, color-coded by stream order on THEMIS daytime infrared mosaic. (d) Detail of the network showing a densely dissected landscape and bifurcating valleys. (e) Elevation profile based on HRSC data, moving average using a $10 \mathrm{~km}$ window (plotted with $1000 \mathrm{~m}$ vertical offset) and slopes of two segments. Location of this profile is the first order valley indicated in (c).

periments combined with previous experimental work, modeling results and theoretical considerations. The main landscape properties are the distribution of valley lengths, valley order, valley orientation and the angle between valley segments. We close the discussion with an interpretation of the Martian valleys described using the proposed landscape metrics framework.

\subsection{Scalability of experimental results}

The experiments described in this paper are not dimensionally scaled or direct analogues to the Martian case studies. Instead, the experiments provide insights into the fundamental processes that result from groundwater seepage and the resultant morphology. These experiments were devised to contrast distinct sources of groundwater and complement previous work. The experimental setup was designed to be simple in order to show clearly the effect of different hydrological boundary conditions. Different initial conditions will produce different landscapes, but again, our work is focused on the essential underlying processes and representative morphological features.

The experiments presented in this paper, and previous work on seepage erosion, applies to landscapes formed by groundwater and thus landscapes that form in porous and erodible material. The overall patterns are expected to be similar on different scales and for different materials that meet these conditions, but details will differ. Our analyses are therefore limited to the large-scale patterns in the landscapes and not expected to explain details. Below we point out the scale effects in our experiments and how we take these into account.

An important difference between the distant source and local precipitation experiments was the steepness of the valley heads and side walls, which were much steeper in the distant source case. In the distant source experiment, the groundwater table was deeper, resulting in an unsaturated (moist) top 


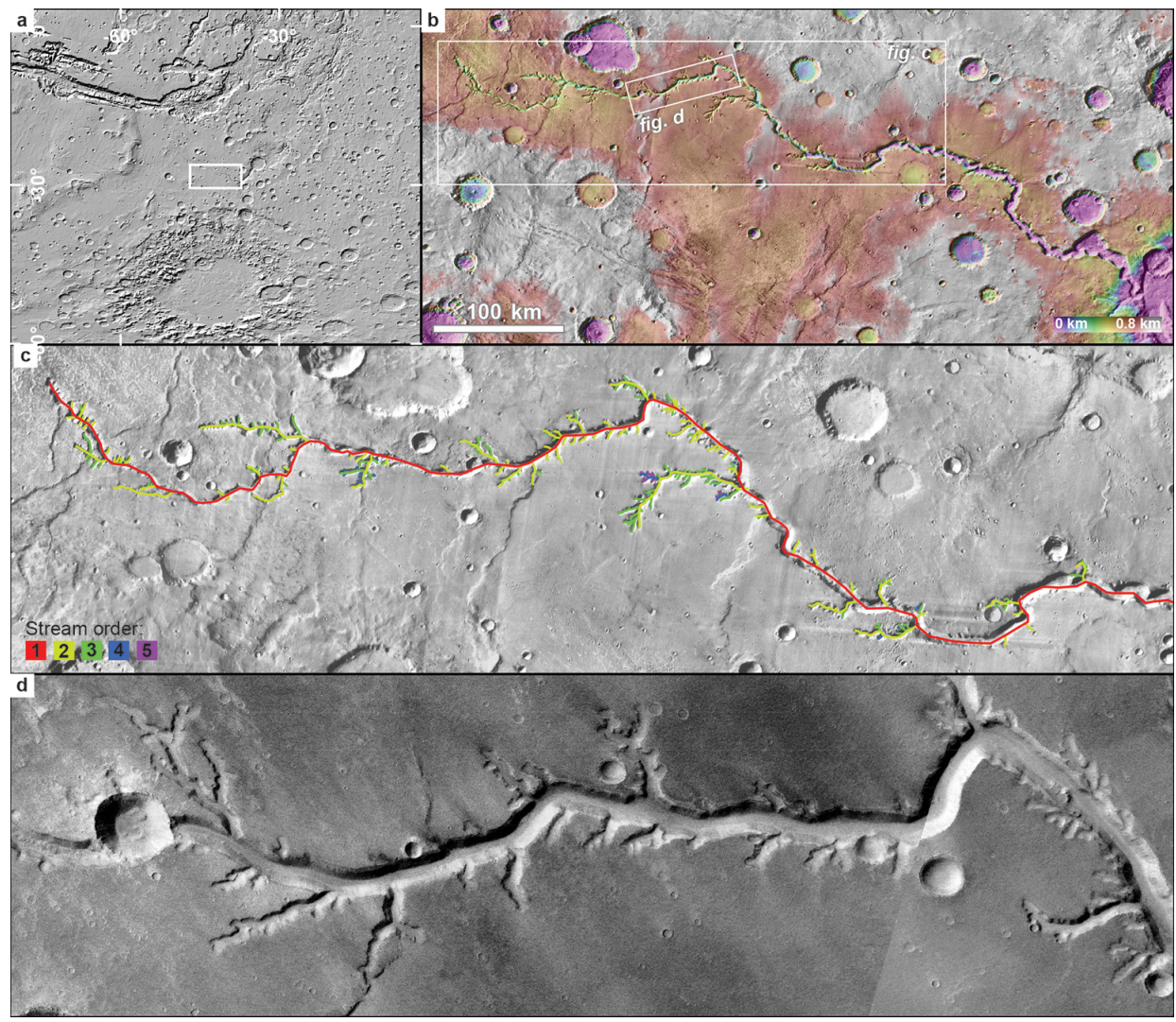

Figure 11. Maps of Nirgal Vallis. (a) Overview map showing location of (b) (MOLA shaded relief). (b) THEMIS daytime infrared mosaic with color-coded MOLA DEM, showing location of (c) and (d). (c) Valley centerlines, color-coded by stream order on THEMIS daytime infrared mosaic. (d) Detail of the network showing a sparsely dissected landscape with many small and a few large valleys.

layer above the groundwater table, which has more apparent cohesion than the saturated (wet) top layer in the local precipitation experiment. In natural systems, such contrasts in material strength arise from differences in soil or substrate properties rather than formative processes. The depth of the unsaturated layer relates to capillary forces, which are scaleindependent and thus relatively small for large experimental valleys (see discussion in Marra et al., 2014a). Nevertheless, theater-head formation took place in both cases with and without an unsaturated top layer, which indicates that this process takes place under both conditions and is not the result of this scale effect.

Destabilization of the headwall is a necessary condition for the development of valleys by seepage. This only takes place if sufficient sediment is removed from the toe of the headwall, which requires channels with enough discharge for sediment erosion and transport along the entire valley length. In previous smaller-scale experiments, Marra et al. (2014a) report on experiments in a $1 \times 3 \mathrm{~m}$ flume with sand where the channels clogged and valleys ceased developing due to the absence of downstream sediment removal. Their solution to sustain upstream processes and valley formation was to flush away sediment at the downstream end. In that same setup, valleys from groundwater seepage did develop when lightweight plastic sediment was used, which enabled sufficient sediment transport due to the lower material density. In other words, sufficient downstream erosion by fluvial processes is essential to keep the formation of valleys by seepage going. In the experiments described in this paper, sediment was not flushed at the downstream end, which shows that the scale effect of having a insufficient discharge for sediment erosion and transport was overcome in our setup.

Additional work is required to understand the morphological details of valleys formed by groundwater seepage. In particular, we expect important effects on valley shapes to result from layered substrates with alternations in material erodibility. These effects can be studied experimentally, but to model erosion rates on larger scales than can be represented in the laboratory, numerical modeling will be more informative about the formative timescales of such systems and may elucidate on terraces found in Martian valley systems. Furthermore, using such models, Martian scenarios with a thick layer of permafrost can be simulated which are unpractical to recreate in most laboratories. 

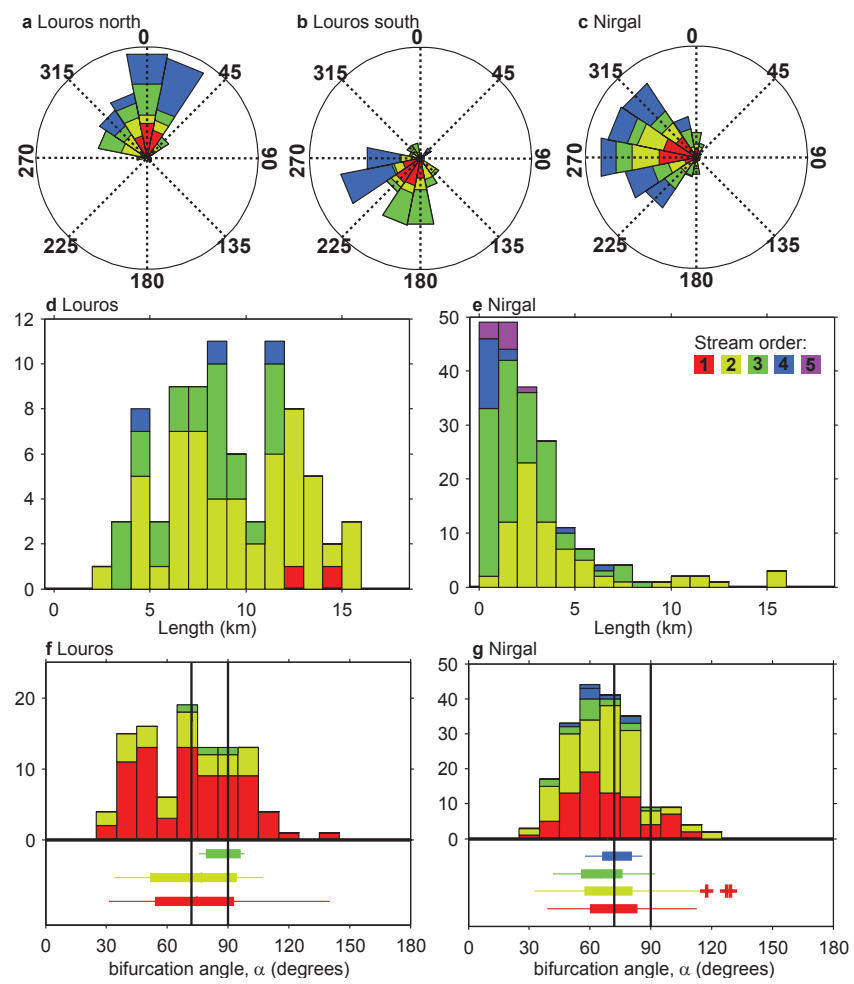

Figure 12. Landscape metrics of Louros Valles and Nirgal Vallis. (a-c) Valley orientation for valleys on the north (a) and south flank (d) of Louros Valles and Nirgal Vallis (c). (d-e) Valley length (distance to lower-order valley) distribution for different stream orders, most main valleys (order 1) plot far outside the shown window for (d) Louros Valles and (e) Nirgal Vallis. (f-g) Distribution of bifurcation orientation and box plots per stream order for (f) Louros Valles and (g) Nirgal Vallis.

\subsection{Groundwater flow piracy, valley spacing and length distribution}

The morphology of the entire landscape shows important differences that are related to subsurface groundwater flow processes. In the distant source experiment, a decreasing number of valleys remained active when smaller valleys ceased to develop. This behavior relates to groundwater flow piracy by the larger valleys, since these depressions attract groundwater. Due to the travel distance and direction of the groundwater, areas downstream of large valleys receive less or even no groundwater as shown by surfacing drying. The resulting landscape consists of several small valleys with a terminated groundwater supply (Fig. 5a) in between a few large active valleys oriented towards the groundwater source (Fig. 13a). In contrast, the local precipitation experiments did not feature groundwater flow piracy since the groundwater source is distributed everywhere and therefore cannot be captured by nearby valleys. The resulting landscape is densely dissected with valleys of similar size in close proximity to each other (Figs. 5b and 13b).
An important parameter for groundwater flow piracy is the fraction of the groundwater flow that a valley captures. This is controlled by the ratio of cross-stream to downstream groundwater flux (Pelletier, 2003; Schorghofer et al., 2004), which is proportional to the groundwater gradient in isotropic conditions. In the case of valleys formed by groundwater seepage, the emerging valley itself leads to a topographic low that introduces a cross-stream groundwater slope, which increases the flow towards that valley. This morphological feedback causes flow piracy when a valley attracts enough groundwater to cease the flow to other valleys. This feedback and tendency for flow piracy is stronger for flat surfaces in contrast to valley formation on a slope, since a depression in a flat surface has a larger effect on the convergence of groundwater flow (Pornprommin et al., 2010).

Our experiments show that the valley width-to-length ratio is similar for valleys formed by a distant source of groundwater (Fig. 8a), but this is not the case for valleys fed by a local groundwater source (Fig. 8a). The similarity in the development of several distally fed valleys is indicative of valley formation by the same source of groundwater. The size of the valley is the dominant control on the amount of water delivered to that valley since a larger and deeper valley yields more groundwater seepage. In turn, the amount of erosion relates to the size of the valley, and hence the morphological development is similar for the different valleys. The amount of water delivered to the valleys fed by local precipitation is only partly controlled by this mechanism. In this case, the amount of groundwater delivered to the valley head also depends on upstream area and local watersheds.

Initial conditions may affect the location where channels emerge and valleys start to form, and thereby the spacing of valleys in the final landscape. In our distant after local experiment with minor initial morphology and a distant groundwater source, the initiation of valleys was related to the initial perturbation of the surface, but the resulting processes and the final landscape was similar to the experiment with no initial perturbations. This shows that seepage is robustly driven by the subsurface flow pattern and agrees with the observations of Schumm and Phillips (1986) that valleys of a composite origin dominantly reflect the last process. In contrast, in the local after distant experiment, there was a significant effect of the initial morphology as old valleys reactivated. Importantly, the valley patterns in the distant after local experiment are similar to those in the distant source experiment; thus, they are hardly influenced by the initial morphology. An implication is that the location and orientation of valleys fed from a distant source strongly relates to the responsible hydrology and, to a lesser extent, to initial condition. Therefore, the morphology is a reliable indicator for the source of groundwater that shaped such landscapes. 


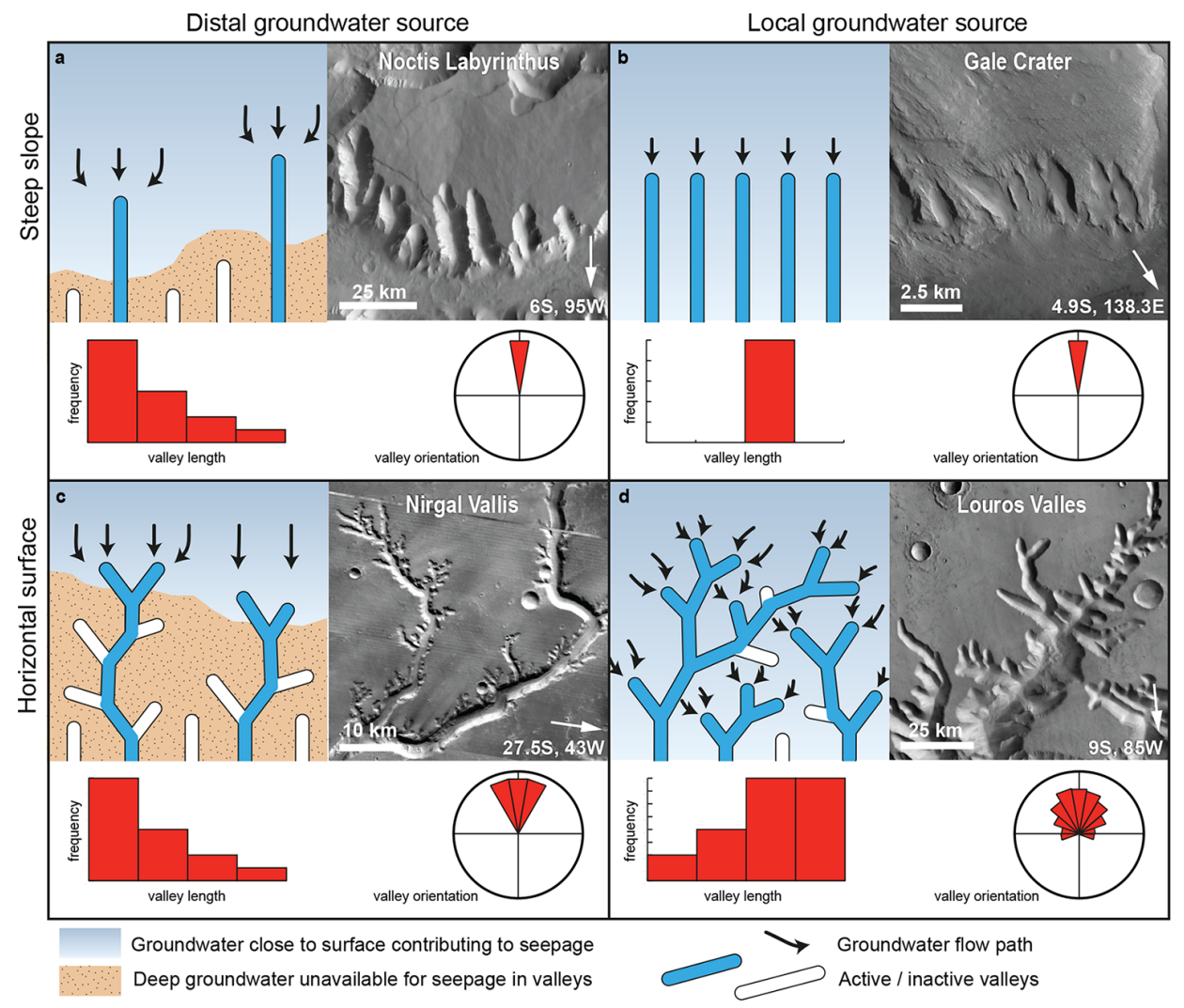

Figure 13. Landscape end members formed by groundwater seepage as result from a distant source or local precipitation, and steep or horizontal surface. Each panel shows a schematic diagram (upper left), an Martian case showing a similar morphology (upper right) as an example, and the expected valley length distribution and valley orientation (bottom). A distant source (a, c) results in valley abandonment due to upstream capture of groundwater, whereas a local groundwater source $(\mathbf{b}, \mathbf{d})$ is less prone to flow piracy. Horizontal surfaces $(\mathbf{c}, \mathbf{d})$ have a strong tendency to form valley bifurcations in contrast to steep slopes (a, b). Valleys emerging from a distant groundwater source result in an open landscape as no valleys develop downstream of large valleys. Similar Martian landscapes in (a) Noctis Labyrinthus (THEMIS image), (b) Gale Crater (CTX image), (c) Nirgal Vallis (THEMIS image) and (d) Louros Valles (THEMIS image).

\subsection{Headward bifurcations}

Our experimental valleys did not bifurcate at their valley head, which is considered a typical property for valleys fed by groundwater seepage (e.g., Howard and McLane, 1988). The absence of headward bifurcations in our experiments is the result of the steep slope in the downstream half of the setup. Pornprommin et al. (2010) showed that valleys that formed in a flat surface result in more seepage at the flanks of the valley head, which increased the tendency of the valleys to split when growing in a headward direction. Our results show that seepage on a steep slope suppresses the tendency to form such headward bifurcations, compared with similar experiments on horizontal surfaces, which do show headward bifurcations (Fig. 13a and c; e.g., Berhanu et al., 2012).

Besides the initial slope, Berhanu et al. (2012) showed that valleys fed from a local source have a higher tendency to bifurcate in a headward direction. This tendency relates to the groundwater flow that enters the valley head from a wide range of directions and not mainly from upstream or the direction of the groundwater source. As a result, valleys formed by seepage from a local source on a flat topography have many headward bifurcations, which results in a densely dissected landscape (Fig. 13d). This pattern is similar to the Apalachicola Bluffs (Florida), which have been shown to be formed by seepage of locally infiltrated precipitation (Abrams et al., 2009).

The flow field that results from local infiltration into a flat substrate results in headward bifurcation angles of $72^{\circ}$ (Devauchelle et al., 2012). This value has been considered as evidence for a groundwater origin of Nirgal Vallis by Glines and Fassett (2013), but this value is only characteristic for seepage from uniform precipitation on a flat surface and is therefore not universally applicable. Furthermore, structural controls from tectonics may also dictate the angles between valleys (Luo et al., 1997), which is also likely the case for Nirgal Vallis (Glines and Fassett, 2013).

The combined occurrence of developing headward bifurcations and groundwater flow piracy results in the formation of typically stubby tributaries. When a valley bifurcates in 
a headward direction, there are two valley heads close to each other, which will in result in abandonment of one of these (Fig. 13c) due to the presence of groundwater flow piracy. This behavior and the resulting morphology is indicative of valley formation by seepage from a distant groundwater source.

\subsection{Origin of Martian examples}

We analyzed the landscape of Louros Valles and Nirgal Vallis, two valley systems often attributed to groundwater seepage. Two additional examples are shown in Fig. 13a and b, and these examples are described below to serve as an illustration of how the morphology can appear but are not analyzed further. The valleys in Noctis Labyrinthus (Fig. 13a) show valleys with no headward bifurcations and a few small valleys in between larger valleys. Although the plateau where these valleys cut into is flat, there is a strong gradient between valley head and outflow point, which illustrates our contention that a steep slope suppresses the tendency for headward bifurcation to form. The small valleys in Gale Crater (Fig. 13b) are similar in size and shallow, and there is a regional slope.

Alternate hypotheses for similar valley formations are bedrock erosion by catastrophic release of surface water (Lamb et al., 2006) or bedrock weathering and erosion by groundwater (Pelletier and Baker, 2011), which would result in the same combination of boundary conditions and morphology as seepage in unconsolidated materials. Another hypothesis for the formation of Louros Valles is focused erosion by meltwater in between patches protected from erosion by the presence of an ice cover ("glacial selective linear erosion"; Lee, 2000).

The evidence in favor of a groundwater origin over surface flow in both Nirgal Vallis and Louros Valles is the absence of remnants of channels feeding the main valleys. However, billions of years of weathering and a dust cover could have obscured such small morphological features. The elevation profile of one of the valleys in Louros Valles is bumpy (Fig. 10e), likely due to later activity. Consequently, the interpretation of such a profile in comparison to elevation profiles of the experiments (Fig. 6) is limited. Therefore, we use the properties of multiple valleys and valley segments in the entire landscape rather than single-valley morphology for our interpretation.

The orientation of valley segments of Louros Valles is diverse and has a broad range of valley lengths, resulting in a densely dissected landscape (Fig. 10). Such a landscape is typical for a local groundwater source (Fig. 13d). Furthermore, in Louros Valles, some higher-order valley segments are oriented in the downstream direction with respect of the main valleys (Fig. 10d), which can be the result of a local source of groundwater and not groundwater coming from greater distances. Additionally, the presence of valleys on both sides of Valles Marineris suggests a local groundwater source and not groundwater coming from a great distance.

A possible local source of groundwater for Louros Valles is precipitation; melt of snow, ice or permafrost; or upwelling groundwater from a cryosphere-confined aquifer (e.g., Clifford, 1993). The presence of this type of aquifer in this region may also have been the source of water for the outflow channels further northeast which are likely to have formed by the release of pressurized groundwater from a confined aquifer. The timing of events here is crucial since the presence of Valles Marineris, and the clear formation of Louros Valles after the opening of Valles Marineris, suggests that this aquifer was at that point cut off and split between the north and south. Seepage at Louros Valles rather than the formation of an outflow channel could represent low aquifer pressure, which fits a trend of lower groundwater pressures at higher elevations in Ophir and Lunae Plana (Marra et al., 2015). Furthermore, the subsidence of Valles Marineris into the aquifer may have been a trigger for outflow or upwelling of groundwater. This hypothesis could be further explored and the asymmetry between the valleys on the north and south flank may provide additional insight into the nature of such an aquifer.

The landscape of Nirgal Vallis is an example of valley formation by seepage from a distant source, given the large number of small valleys typical for groundwater flow piracy (Figs. 11, 5a, 13a and c). The groundwater source was likely to have been west of the valley due to the orientation of most valleys towards that direction. A possible source of groundwater flow from the west could be recharge in the Tharsis region (Harrison and Grimm, 2004). Seepage of groundwater likely took place before the formation of a global confining cryosphere, which is considered a requirement for aquifer pressurization for Martian outflow channels in the Hesperian (Clifford, 1993; Marra et al., 2014b). Alternatively, a regional discontinuity may be the reason for seepage at Nirgal Vallis. In that case, seepage took place during an early stage in the formation of the cryosphere. The climatic implications are the presence of precipitation in the source region which could be aqueous or icy (Wordsworth et al., 2013), but widespread precipitation is not required and a groundwater system as the dominant element of the hydrology shows that these valleys could form in the absence of a long-lived hydrological cycle at the surface.

Based on our and previous experiments, this study now provides a framework that links landscape properties to the groundwater source location. The two Martian examples shown further illustrate this link. Although different processes could produce similar valley morphologies, the strong correspondence of the landscape metrics of these examples and those produced by seepage points towards a groundwater origin. In particular the distant groundwater source of Nirgal Vallis implies a well-developed groundwater system. Perhaps most significantly, outflow of groundwater and resulting valley formation of such a system could have taken place re- 
gardless of climate conditions being optimal for the sustained presence of liquid water on the surface.

\section{Conclusions}

We studied groundwater seepage processes and subsequent valley formation using a series of large sandbox experiments. Our experiments focused on the difference between valleys fed from groundwater originating from a distant source or from infiltrated local precipitation. In both cases, valley heads developed in a headward direction by mass-wasting processes triggered by steepening due to fluvial sediment transport through active channels out of the valley.

Combined with previous experimental work, we provide a framework of driving processes and resulting landscape metrics for valleys fed by a distant source and local precipitation, and for a steep and flat topography. Their main characteristics are as follows. (1) Due to groundwater flow piracy, seepage erosion from a distant groundwater source results in a sparsely dissected landscape with a few large and many small valleys. Valleys fed from a local source of groundwater, e.g., precipitation, are not characterized by flow piracy and have a range sizes, resulting in a densely dissected landscape. (2) Valley formation in horizontal surfaces promotes the development of headward bifurcations in contrast to steep surfaces where this tendency is suppressed. For valleys fed by a distant source of groundwater, the combined occurrence of bifurcating valleys and flow piracy results in valley systems with stubby tributaries. Valleys fed by locally infiltrated groundwater on horizontal surfaces grow in a wide range of directions due to the development of many headward bifurcations which remain morphologically active.

As an example, we applied these characteristics to two Martian systems. Firstly, Louros Valles shows a densely dissected landscape with a broad range of valley orientations and valley lengths. This landscape is typical for a local groundwater source. Such a local source could relate to an aquifer that fed the outflow channels, but is more likely related to local precipitation or melt of ice or snow. Secondly, Nirgal Vallis illustrates a sparsely dissected landscape with many small, and only a few large, valleys with a single dominant orientation. This indicates a distant groundwater source in the west, which is likely produced from recharge at Tharsis. Further study of similar landscape properties as a result of overland flow is required to advance the ambiguous interpretation of these valleys.

\section{The Supplement related to this article is available online at doi:10.5194/esurf-3-389-2015-supplement.}

Author contributions. W. A. Marra, E. Hauber and M. G. Kleinhans conceived the study; W. A. Marra, S. J. McLelland, B. J. Mur- phy, D. R. Parsons and M. G. Kleinhans designed the experiments; W. A. Marra performed analyses and interpretation; W. A. Marra, E. Hauber and M. G. Kleinhans discussed the results with contributions from all other authors; W. A. Marra wrote the paper.

Acknowledgements. This work is part of the $\mathrm{PhD}$ research of W. A. Marra, financially supported by NWO grant ALW-GO-PL/10 01. We thank the anonymous reviewer and Paul Carling for providing very helpful comments on the initial discussion paper, and associate editor Mary Bourke for handling our manuscript. The authors are grateful for the time-lapse camera triggering device built by Henk Markies and for the help from Tjalling de Haas, Steven de Jong, Leiping Ye, Chris Unsworth, Susan Conway and Rob Thomas in running the experiments, and are grateful to Tjalling de Haas for reviewing a draft of this paper. Experimental data are available upon request from W. A. Marra (w.a.marra@uu.nl) or M. G. Kleinhans (m.g.kleinhans@uu.nl).

Edited by: M. Bourke

\section{References}

Abrams, D. M., Lobkovsky, A. E., Petroff, A. P., Straub, K. M., McElroy, B., Mohrig, D. C., Kudrolli, A., and Rothman, D. H.: Growth laws for channel networks incised by groundwater flow, Nat. Geosci., 2, 193-196, doi:10.1038/ngeo432, 2009.

Agisoft: Agisoft PhotoScan User Manual: Professional Edition, Version 1.0, available at: http://www.agisoft.com/ (last access: 10 January 2014), 2014.

Berhanu, M., Petroff, A., Devauchelle, O., Kudrolli, A., and Rothman, D. H.: Shape and dynamics of seepage erosion in a horizontal granular bed, Phys. Rev. E, 86, 041304-1-041304-9, doi:10.1103/PhysRevE.86.041304, 2012.

Clifford, S. M.: A model for the hydrologic and climatic behavior of water on Mars, J. Geophys. Res., 98, 10973, doi:10.1029/93JE00225, 1993.

Craddock, R. A., Howard, A. D., Irwin, R. P., Tooth, S., Williams, R. M. E., and Chu, P.-S.: Drainage network development in the Keanakāko'i tephra, Kîlauea Volcano, Hawai'i: implications for fluvial erosion and valley network formation on early Mars, J. Geophys. Res., 117, 1-19, doi:10.1029/2012JE004074, 2012.

Devauchelle, O., Petroff, A. P., Lobkovsky, A. E., and Rothman, D. H.: Longitudinal profile of channels cut by springs, J. Fluid Mech., 667, 38-47, doi:10.1017/S0022112010005264, 2011.

Devauchelle, O., Petroff, A. P., Seybold, H. F., and Rothman, D. H.: Ramification of stream networks., P. Natl. Acad. Sci. USA, 109, 20832-20836, doi:10.1073/pnas.1215218109, 2012.

Dunne, T.: Formation and controls of channel networks, Prog. Phys. Geog., 4, 211-239, doi:10.1177/030913338000400204, 1980.

Fergason, R., Lee, E. M., and Weller, L.: Themis geodetically controlled mosiacs of Mars, Lunar Planet. Sci. Conf., XLIV, 18-22 March 2013, abstract 1642, The Woodlands, Texas, 2013.

Forsyth, D. A. and Ponce, J.: Computer Vision: a Modern Approach, 2nd Edn., Prentice Hall, Upper Saddle River, New Jersey, 762 pp., 2011. 
Fox, G. A. and Wilson, G. V.: The role of subsurface flow in hillslope and stream bank erosion: a review, Soil Sci. Soc. Am. J., 74, 717-733, doi:10.2136/sssaj2009.0319, 2010.

Fox, G. A., Wilson, G. V., Periketi, R. K., and Cullum, R. F.: Sediment transport model for seepage erosion of streambank sediment, J. Hydraul. Eng.-ASCE, 11, 603-611, doi:10.1061/(ASCE)1084-0699(2006)11:6(603), 2006.

Glines, N. and Fassett, C. I.: Evidence for Groundwater Sapping on Mars from Junction Angles of Nirgal Vallis Tributaries, in: Lunar Planet. Sci. Conf., Vol. XLIV, 18-22 March 2013, p. abstract 2011, The Woodlands, Texas, 2013.

Hack, J. T.: Studies of Longitudinal Stream Profiles in Virginia and Maryland, US Geol. Suvey Prof. Pap., 294-B, Washington DC, 45-95, 1957.

Hagerty, D. J.: Piping/sapping erosion. I: Basic considerations, J. Hydraul. Eng.-ASCE, 117, 991-1008, doi:10.1061/(ASCE)0733-9429(1991)117:8(991), 1991.

Harrison, K. P. and Grimm, R. E.: Tharsis recharge: A source of groundwater for Martian outflow channels, Geophys. Res. Lett., 31, L14,703, doi:10.1029/2004GL020502, 2004.

Harrison, K. P. and Grimm, R. E.: Groundwater-controlled valley networks and the decline of surface runoff on early Mars, J. Geophys. Res., 110, E12S16, doi:10.1029/2005JE002455, 2005.

Harrison, S., Balme, M., Hagermann, A., Murray, J., Muller, J.P., and Wilson, A.: A branching, positive relief network in the middle member of the Medusae Fossae Formation, equatorial Mars-Evidence for sapping?, Planet. Space Sci., 85, 142-163, doi:10.1016/j.pss.2013.06.004, 2013.

Higgins, C. G.: Drainage systems developed by sapping on Earth and Mars, Geology, 10, 147-152, doi:10.1130/00917613(1982)10<147:DSDBSO>2.0.CO;2, 1982.

Howard, A. D. and Kochel, R. C.: Introduction to Cuesta landforms and sapping processes on the Colorado Plateau, in: Sapping Featur. Color. Plateau, edited by: Howard, A. D., Kochel, R. C., and Holt, H. R., chap. 2, 6-56, NASA Spec. Publ. 491, Washington DC, 1988.

Howard, A. D. and McLane, C. F.: Erosion of cohesionless sediment by groundwater seepage, Water Resour. Res., 24, 16591674, doi:10.1029/WR024i010p01659, 1988.

Irwin, R. P., Tooth, S., Craddock, R. A., Howard, A. D., and de Latour, A. B.: Origin and development of theater-headed valleys in the Atacama Desert, northern Chile: morphological analogs to Martian valley networks, Icarus, 243, 296-310, doi:10.1016/j.icarus.2014.08.012, 2014.

Jaumann, R. and Reiss, D.: Nirgal Vallis: evidence for Extensive Sapping, in: Lunar Planet. Sci. Conf., 11-15 March 2002, p. abstract 1579, The Woodlands, Texas, 2002.

Jaumann, R., Neukum, G., Behnke, T., Duxbury, T., Eichentopf, K., Flohrer, J., Gasselt, S., Giese, B., Gwinner, K., Hauber, E., Hoffmann, H., Hoffmeister, a., Köhler, U., Matz, K.-D., McCord, T., Mertens, V., Oberst, J., Pischel, R., Reiss, D., Ress, E., Roatsch, T., Saiger, P., Scholten, F., Schwarz, G., Stephan, K., and Wählisch, M.: The high-resolution stereo camera (HRSC) experiment on Mars Express: instrument aspects and experiment conduct from interplanetary cruise through the nominal mission, Planet. Space Sci., 55, 928-952, doi:10.1016/j.pss.2006.12.003, 2007

Kochel, R. C. and Piper, J. F.: Morphology of large valleys on Hawaii: evidence for groundwater sapping and com- parisons with Martian valleys, J. Geophys. Res., 91, E175, doi:10.1029/JB091iB13p0E175, 1986.

Laity, J. E. and Malin, M. C.: Sapping processes and the development of theater-headed valley networks on the Colorado Plateau, Geol. Soc. Am. Bull., 96, 203-217, doi:10.1130/00167606(1985)96\%3C203:SPATDO\%3E2.0.CO;2, 1985.

Lamb, M. P., Howard, A. D., Johnson, J., Whipple, K. X., Dietrich, W. E., and Perron, J. T.: Can springs cut canyons into rock, J. Geophys. Res., 111, 7002, doi:10.1029/2005JE002663, 2006.

Lee, P.: Selective fluvial erosion on mars: glacial selective linear erosion on Devon island, Nunavut, arctic Canada, as a possible analog, Lunar Planet. Sci. Conf., XXXI, 13-17 March 2000, abstract 2080, The Woodlands, Texas, 2000.

Lobkovsky, A. E., Jensen, B., Kudrolli, A., and Rothman, D. H.: Threshold phenomena in erosion driven by subsurface flow, J. Geophys. Res., 109, 1-10, doi:10.1029/2004JF000172, 2004.

Luo, W., Arvidson, R. E., Sultan, M., Becker, R., Katherine Crombie, M., Sturchio, N., and El Alfy, Z.: Ground-water sapping processes, Western Desert, Egypt, Geol. Soc. Am. Bull., 109, 43-62, doi:10.1130/0016-7606(1997)109<0043:GWSPWD>2.3.CO;2, 1997.

Mangold, N. and Ansan, V.: Detailed study of an hydrological system of valleys, a delta and lakes in the Southwest Thaumasia region, Mars, Icarus, 180, 75-87, doi:10.1016/j.icarus.2005.08.017, 2006.

Marra, W. A., Braat, L., Baar, A. W., and Kleinhans, M. G.: Valley formation by groundwater seepage, pressurized groundwater outbursts and crater-lake overflow in flume experiments with implications for Mars, Icarus, 232, 97-117, doi:10.1016/j.icarus.2013.12.026, 2014a.

Marra, W. A., Hauber, E., McLelland, S. J., Murphy, B. J., Parsons, D. R., Conway, S. J., Roda, M., Govers, R., and Kleinhans, M. G.: Pressurized groundwater outflow experiments and numerical modeling for outflow channels on Mars, J. Geophys. Res.-Planet., 119, 2668-2693, doi:10.1002/2014JE004701, 2014b.

Marra, W. A., Kleinhans, M. G., and Addink, E. A.: Network concepts to describe channel importance and change in multichannel systems: test results for the Jamuna River, Bangladesh, Earth Surf. Proc. Land., 39, 766-778, doi:10.1002/esp.3482, 2014c.

Marra, W. A., Hauber, E., de Jong, S. M., and Kleinhans, M. G.: Pressurized groundwater systems in Lunae and Ophir Plana (Mars): insights from small-scale morphology and experiments, in: Martian groundwater outflow processes and morphology: reconstruction of paleohydrology using landscape evolution experiments, Utrecht Studies in Earth Sciences, 81, Chapter 5, PhD Thesis by: Marra, W. A., available at: http://dspace.library.uu.nl/ handle/1874/311674, ISBN978-90-6266-393-4, 2015.

Otvos, E. G.: Rain-induced beach processes; landforms of ground water sapping and surface runoff, J. Coastal Res., 15, 1040-1054, 1999.

Pelletier, J. D.: Drainage basin evolution in the Rainfall Erosion Facility: dependence on initial conditions, Geomorphology, 53, 183-196, doi:10.1016/S0169-555X(02)00353-7, 2003.

Pelletier, J. D. and Baker, V. R.: The role of weathering in the formation of bedrock valleys on Earth and Mars: a numerical modeling investigation, J. Geophys. Res., 116, 1-13, doi:10.1029/2011JE003821, 2011. 
Pornprommin, A., Takei, Y., Wubneh, A. M., and Izumi, N.: Channel inception in cohesionless sediment by seepage erosion, J. Hydro-Env. Res., 3, 232-238, doi:10.1016/j.jher.2009.10.011, 2010.

Schorghofer, N., Jensen, B., Kudrolli, A., and Rothman, D. H.: Spontaneous channelization in permeable ground: theory, experiment, and observation, J. Fluid Mech., 503, 357-374, doi:10.1017/S0022112004007931, 2004.
Schumm, S. A. and Phillips, L.: Composite channels of the Canterbury Plain, New Zealand: a Martian analog?, Geology, 14, 326, doi:10.1130/0091-7613(1986)14<326:CCOTCP>2.0.CO;2, 1986.

Wordsworth, R., Forget, F., Millour, E., Head, J. W., Madeleine, J.B. Charnay, B.: Global modelling of the early martian climate under a denser $\mathrm{CO}_{2}$ atmosphere: Water cycle and ice evolution, Icarus, 222, 1-19, doi:10.1016/j.icarus.2012.09.036, 2013. 